\title{
Interstellar chemistry of nitrogen hydrides in dark clouds ${ }^{\star}$
}

\author{
R. Le Gal ${ }^{1}$, P. Hily-Blant ${ }^{1,2}$, A. Faure ${ }^{1}$, G. Pineau des Forêts ${ }^{3,4}$, C. Rist ${ }^{1}$, and S. Maret ${ }^{1}$ \\ ${ }^{1}$ Université Joseph Fourier/CNRS, Institut de Planétologie et d'Astrophysique de Grenoble (IPAG) UMR 5274, 38041 Grenoble, \\ France \\ e-mail: [romane.legal; pierre.hily-blant; alexandre.faure]@obs.ujf-grenoble.fr \\ 2 Institut Universitaire de France, France \\ 3 Université de Paris-Sud/CNRS, IAS (UMR 8617), 91405 Orsay Cedex, France \\ ${ }^{4}$ LERMA/CNRS (UMR 8112)/Observatoire de Paris, 75014 Paris, France
}

Received 29 July 2013 / Accepted 18 November 2013

\begin{abstract}
Nitrogen, amongst the most abundant metals in the interstellar medium, has a peculiar chemistry that differs from those of carbon and oxygen. Recent observations of several nitrogen-bearing species in the interstellar medium suggest abundances in sharp disagreement with current chemical models. Although some of these observations show that some gas-grain processes are at work, gas-phase chemistry needs first to be revisited. Strong constraints are provided by recent Herschel observations of nitrogen hydrides in cold gas. The aim of the present work is to comprehensively analyse the interstellar chemistry of nitrogen, focussing on the gas-phase formation of the smallest polyatomic species and, in particular, on nitrogen hydrides. We present a new chemical network in which the kinetic rates of critical reactions have been updated based on recent experimental and theoretical studies, including nuclear spin branching ratios. Our network thus treats the different spin symmetries of the nitrogen hydrides self-consistently, together with the ortho and para forms of molecular hydrogen. This new network is used to model the time evolution of the chemical abundances in dark cloud conditions. The steady-state results are analysed, with special emphasis on the influence of the overall amounts of carbon, oxygen, and sulphur. Our calculations are also compared with Herschel/HIFI observations of $\mathrm{NH}, \mathrm{NH}_{2}$, and $\mathrm{NH}_{3}$ detected towards the external envelope of the protostar IRAS 16293-2422. The observed abundances and abundance ratios are reproduced for a $\mathrm{C} / \mathrm{O}$ gas-phase elemental abundance ratio of $\sim 0.8$, provided that the sulphur abundance be depleted by a factor greater than 2 . The ortho-to-para ratio of $\mathrm{H}_{2}$ in these models is $\sim 10^{-3}$. Our models also provide predictions for the ortho-to-para ratios of $\mathrm{NH}_{2}$ and $\mathrm{NH}_{3}$ of $\sim 2.3$ and $\sim 0.7$, respectively. We conclude that the abundances of nitrogen hydrides in dark cloud conditions are consistent with the gas-phase synthesis predicted with our new chemical network.
\end{abstract}

Key words. astrochemistry - ISM: abundances - ISM: molecules

\section{Introduction}

Nitrogen-bearing species have commonly been observed in the interstellar medium (ISM) ever since the discovery of ammonia, the first polyatomic interstellar species, by Cheung et al. (1968). Nitrogenated species are useful probes of the physics and chemistry of the ISM over a broad range of conditions. Inversion lines of ammonia serve as temperature probes in molecular clouds (Ho \& Townes 1983; Maret et al. 2009) and rotational lines of diazenylium $\left(\mathrm{N}_{2} \mathrm{H}^{+}\right)$and its deuterated isotopologue, $\mathrm{N}_{2} \mathrm{D}^{+}$, may be used at much higher densities $\left(n \sim 10^{5} \mathrm{~cm}^{-3}\right.$, Pagani et al. 2007; Crapsi et al. 2007). In the diffuse ISM, CN absorption lines allowed the first estimate of the CMB temperature (Thaddeus 1972). Owing to its sensitivity to Zeeman splitting and to its hyperfine structure, $\mathrm{CN}$ is also a powerful tool for measuring the line-of-sight magnetic field intensity in dense regions (Crutcher 2012).

The reservoir of nitrogen in molecular clouds is still controversial, but is expected to be gaseous, either in atomic or molecular forms. Atomic nitrogen in the diffuse ISM is observed through absorption lines in the UV (Nieva \& Przybilla 2012). Searches for the $N_{2}$ molecule in interstellar space have been unfruitful until its first detection in the far-ultraviolet

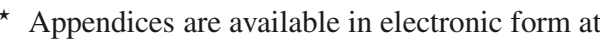
http://www . aanda.org
}

by Knauth et al. (2004), in absorption against the background star HD 124314. The derived column density of $\mathrm{N}_{2}$, $4.6 \times 10^{13} \mathrm{~cm}^{-2}$, is several orders of magnitude lower than that of atomic nitrogen $\left(2.0 \times 10^{17} \mathrm{~cm}^{-2}\right)$, indicating that nitrogen is mainly atomic. The total visual extinction is $1.5 \mathrm{mag}$ or $N_{\mathrm{H}}=$ $2.8 \times 10^{21} \mathrm{~cm}^{-2}$ (assuming standard grain properties), leading to abundances, with respect to hydrogen nuclei, of $7.2 \times 10^{-5}$ and $1.6 \times 10^{-8}$ for atomic and molecular nitrogen, respectively. The column density of $\mathrm{N}_{2}$ is also about one order of magnitude higher than the predictions of $\mathrm{Li}$ et al. (2013) for translucent clouds, which take the photo-dissociation of $\mathrm{N}_{2}$ into account. Strong discrepancy between observations and model predictions suggests that nitrogen chemistry in such diffuse-to-translucent environments remains poorly understood.

In dense molecular clouds, where hydrogen is molecular, the situation is even worse, because $\mathrm{NI}$ and $\mathrm{N}_{2}$ are not observable directly. Constraints on their abundances are thus only indirect. In dense clouds, $\mathrm{N}_{2} \mathrm{H}^{+}$, a direct chemical product of $\mathrm{N}_{2}$, has been observed by Womack et al. (1992) and Maret et al. (2006), who concluded that atomic $\mathrm{N}$ is most likely the dominant reservoir of nitrogen. In addition, in prestellar cores with gas densities $\sim 10^{5} \mathrm{~cm}^{-3}$, Hily-Blant et al. (2010b) derived an upper limit on the gas-phase abundance of atomic nitrogen which suggested that nitrogen may be predominantly hidden in ices coating dust grains. More recently, Daranlot et al. (2012) have found that 
gaseous nitrogen is mostly atomic in dense clouds, but that the dominant reservoir of nitrogen is indeed in the form of ammonia ices at the surface of dust grains. Neverthess, as stressed by these authors, the predicted amount of icy ammonia is larger than what is observed in dark clouds and much larger than what is observed in comets. From the above, one can safely consider that the question of the reservoir of gaseous (and solid) nitrogen in dark clouds still remains an open issue.

In recent years, additional observations have challenged our understanding of the first steps of the chemistry of nitrogen (e.g. Hily-Blant et al. 2010b; Persson et al. 2012). By first steps we here refer to the synthesis of the smallest N-bearing molecules. One such discrepancy between observations and models is shown by the $\mathrm{CN}: \mathrm{HCN}$ abundance ratio towards several starless dark clouds, the value of which is underpredicted in the models of Hily-Blant et al. (2010b). Another concern is the HCN:HNC abundance ratio. These two isomers are the products of the dissociative recombination (hereafter denoted DR) of $\mathrm{HCNH}^{+}$, with equally measured branching ratio (Mendes et al. 2012). The predicted abundance ratio HCN:HNC is thus expected to be close to unity (Herbst et al. 2000). Observed ratios, however, show a large scatter around unity (Hirota et al. 1998) that may reflect different chemical routes to these molecules.

Another fundamental question is how ammonia is formed in dense clouds. Le Bourlot (1991) suggested that the gas-phase synthesis through the $\mathrm{N}^{+}+\mathrm{H}_{2}$ reaction, followed by hydrogen abstractions and DR reactions, was efficient enough to reproduce the observed amounts. Very recently, however, Dislaire et al. (2012) have revisited the experimental data available for the $\mathrm{N}^{+}+\mathrm{H}_{2}$ reaction. The new rate is significantly lower, and it falls below the critical value inferred by Herbst et al. (1987) to explain the observed abundances of ammonia. The efficiency of the gas-phase synthesis of ammonia versus the hydrogenation of atomic nitrogen on the surfaces of dust grains remains an open question (e.g. Tielens \& Hagen 1982; D'Hendecourt et al. 1985; Charnley \& Rodgers 2002; Hidaka et al. 2011). Observational constraints on the amount of ammonia locked into ices coating dust grains are rare, because the $\mathrm{N}-\mathrm{H}$ vibrational feature at $2.95 \mu \mathrm{m}$ is heavily obscured by the $3 \mu \mathrm{m}$ deep water-ice bands. However, observations of $\mathrm{NH}_{3}$ ices in young star formation regions indicate that an abundance of $5 \%$ relative to water seems to be a reasonable value (Bottinelli et al. 2010). Up to now, $\mathrm{N}_{2}$ ices have not been detected in dense regions (Sandford et al. 2001). Perhaps related to the ammonia issue is a new constraint based on the abundance ratios of nitrogen hydrides $\mathrm{NH}: \mathrm{NH}_{2}: \mathrm{NH}_{3}$ towards the Class 0 protostar IRAS 16293-2422, obtained with the HIFI (Heterodyne Instrument for the Far-Infrared) instrument onboard the Herschel satellite in the framework of the CHESS key programme (Ceccarelli et al. 2010). The absorption lines arising from the low-lying rotational levels of these hydrides lead to abundance ratios $\mathrm{NH}: \mathrm{NH}_{2}: \mathrm{NH}_{3}=5: 1: 300$. These abundance ratios could not be reproduced by model calculations in dark gas at a temperature of $10 \mathrm{~K}$ and a gas density of $10^{4} \mathrm{~cm}^{-3}$ (Hily-Blant et al. 2010a). Last, in diffuse-to-translucent environments, Herschel/HIFI observations of the ortho and para forms of ammonia indicate an ortho-to-para ratio of $\sim 0.7$ that could not be explained with the standard nitrogen chemistry (Persson et al. 2012).

The present paper is devoted to the chemistry of nitrogen in dense regions of the ISM that are efficiently shielded from ultraviolet photons by the dust and molecular hydrogen. One major difficulty for progress on the issue of nitrogen chemistry in the dense ISM is that neither $\mathrm{N}$ nor $\mathrm{N}_{2}$ are observable. Determination of their abundances thus relies on observations of trace nitrogen-containing molecules. Chemical models are then essential. Such carriers usually include $\mathrm{NH}_{3}, \mathrm{CN}, \mathrm{HCN}, \mathrm{HNC}$, and $\mathrm{N}_{2} \mathrm{H}^{+}$, together with ${ }^{13} \mathrm{C}, \mathrm{D}$, and ${ }^{15} \mathrm{~N}$ isotopologues, and to a lesser extent NO. For the major isotopologues, the typical abundances with respect to the total $\mathrm{H}$ nuclei are $\approx 10^{-10}-10^{-9}$, except for NO, whose abundance may be as high as $10^{-8}$ (Suzuki et al. 1992; Gerin et al. 1992; Akyilmaz et al. 2007; Hily-Blant et al. 2010b; Padovani et al. 2011).

Chemical models allow predictions to be made for the abundances of chemical species under specified physical conditions (for a review, see Wakelam et al. 2010). Time-dependent models follow the abundances with time, until the steady state is eventually reached. In the ISM, however, the steady state does not coincide with the thermodynamical equilibrium, and models should thus solve the time-dependent chemical and physical equations in a self-consistent fashion (e.g. Tassis et al. 2012). However, a full coupling, e.g. including the impact of the chemical abundances on the thermodynamical state of the gas through radiative transfer, remains beyond current numerical capabilities. Simplifications must be made, such as adopting analytical prescriptions for the time evolution of the gas physical conditions (Bergin \& Langer 1997; Flower et al. 2005). Regarding the chemical processes, the cornerstone of any chemical model is really the network of chemical reactions that describe the formation and destruction of the chemical species. The determination, either theoretically or experimentally, of the kinetic rates of these reactions at the low temperatures prevailing in the diffuse, translucent, and dense ISM $(5-80 \mathrm{~K})$ is extremely timedemanding. This task is simply out of reach for the few thousand reactions involved in current chemical networks. It is thus crucial to identify the key reactions whose rates have a major effect on the chemistry (Wakelam et al. 2010, 2012).

In recent years, to meet the above challenges, rate constants for several key reactions involved in the chemistry of interstellar nitrogen have been computed (e.g. Jorfi et al. 2009; Jorfi \& Honvault 2009) and measured (e.g. Bergeat et al. 2009; Daranlot et al. 2011, 2012) down to $\sim 10$ and $\sim 50 \mathrm{~K}$, respectively. These challenges also triggered theoretical investigations. Separate collisional rates were computed for $\mathrm{HCN}$ and $\mathrm{HNC}$ with $\mathrm{H}_{2}$ by Sarrasin et al. (2010). They show, in particular, very different rates for the (1-0) rotational transition. Using those new rates, Padovani et al. (2011) derived an abundance ratio $\mathrm{HCN}: \mathrm{HNC} \approx 1$ in three starless cores, in agreement with model predictions, suggesting that the current chemical route to $\mathrm{HCN}$ and $\mathrm{HNC}$ is consistent with observations. Further observations are, however, needed to put this result on a firmer basis.

A theoretical investigation of the ortho-para chemistry of ammonia in the cold ISM was done by Rist et al. (2013). They calculated separate branching ratios for the hydrogen abstractions and DR reactions leading to the ortho and para forms of nitrogen hydrides, taking nuclear spin selection rules into account. With these new rates and the new chemical network fully described in this paper, Faure et al. (2013) showed that the orthoto-para ratio of $\sim 0.7$ for ammonia, observed by Persson et al. (2012), is in fact consistent with gas-phase chemistry in a paraenriched $\mathrm{H}_{2}$ gas. In this model the anomalous values of the ortho-to-para ratios of nitrogen hydrides are a consequence of the low ortho-to-para ratio of $\mathrm{H}_{2}$, and result from the conservation of nuclear spin in chemical reactions. In a similar fashion, Dislaire et al. (2012) show that the $\mathrm{NH}: \mathrm{NH}_{2}$ abundance ratio in the envelope of IRAS 16923-2422 can be reproduced only for an ortho-to-para ratio of $\mathrm{H}_{2} \approx 10^{-3}$.

These recent experimental and theoretical results motivated the present work aimed at presenting a new network 


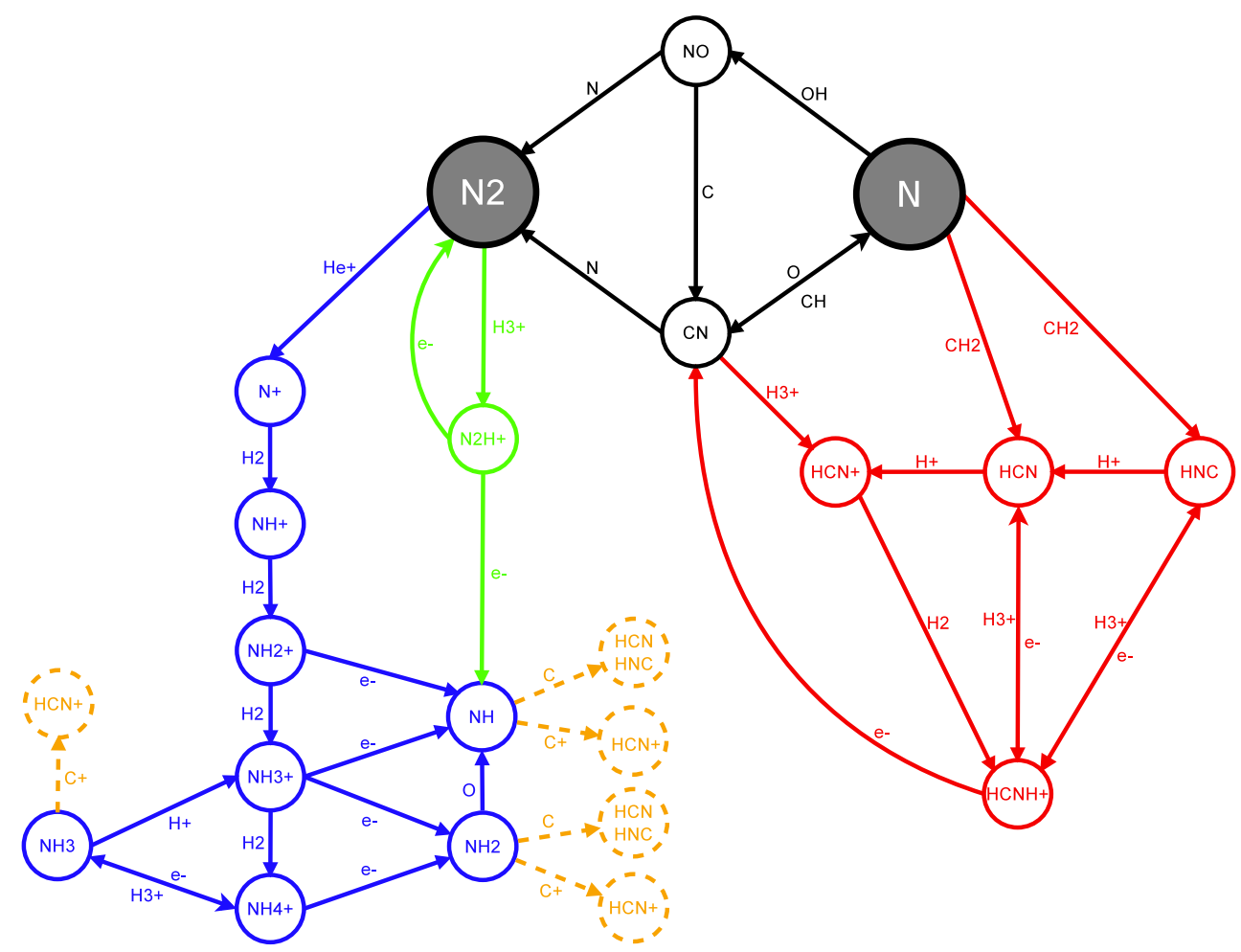

Fig. 1. Principal gas-phase reactions involved in the first stages of nitrogen interstellar chemistry in dark clouds. Nitrogen hydrides (blue, left) and nitriles (red, right) have been clearly separated. The main formation route of $\mathrm{NH}$ is highlighted (green). Chemical pathways from nitrogen hydrides to nitriles, which are efficient at specific $\mathrm{C} / \mathrm{O}$ ratio ranges, are also represented (dashed yellow). Adapted from Hily-Blant et al. (2013a).

of the nitrogen chemistry in dense clouds, thus superseding the classical networks of Herbst \& Klemperer (1973) and Pineau des Forêts et al. (1990). This work puts special emphasis on nitrogen hydrides for which the ortho and para forms are treated self-consistently along with the ortho and para forms of $\mathrm{H}_{2}$. The outline of the paper is as follows. In Sect. 2, we present our new nitrogen network. Section 3 describes our model calculations, with in particular, a discussion of initial abundances. Results and comparisons with Herschel observations of nitrogen hydrides are the subject of Sect. 4. Section 5 summarises our new findings and suggests further lines of investigation.

\section{Chemical network}

\subsection{General considerations}

The formation of nitrogen hydrides $\left(\mathrm{NH}, \mathrm{NH}_{2}\right.$, and $\left.\mathrm{NH}_{3}\right)$ is similar to that of carbon and oxygen hydrides, but has a different origin. First, unlike carbon, $\mathrm{N}^{+}$is not available directly because the ionisation potential of $\mathrm{N}(14.53 \mathrm{eV})$ is greater than that of $\mathrm{H}$. In addition, the reaction $\mathrm{N}+\mathrm{H}_{3}^{+} \rightarrow \mathrm{NH}^{+}+\mathrm{H}_{2}$ - whose analogue is responsible for the production of $\mathrm{CH}^{+}$and $\mathrm{OH}^{+}$in dark gas - is endothermic because the proton affinity of $\mathrm{N}(3.55 \mathrm{eV})$ is lower than that of $\mathrm{H}_{2}(4.38 \mathrm{eV})$. The alternative exothermic pathway, $\mathrm{N}+\mathrm{H}_{3}^{+} \rightarrow \mathrm{NH}_{2}^{+}+\mathrm{H}$, shows a high activation energy (Herbst et al. 1987). As a result, in the current understanding of nitrogen chemistry, the production of $\mathrm{N}^{+}$results from molecular nitrogen reacting with $\mathrm{He}^{+}$. This reaction is found to be more efficient than the direct cosmic-ray ionisation of atomic nitrogen. Once $\mathrm{N}^{+}$is formed, rapid hydrogen-abstraction reactions initiated with

$\mathrm{N}^{+}+\mathrm{H}_{2} \longrightarrow \mathrm{NH}^{+}+\mathrm{H}$ lead to the $\mathrm{NH}^{+}, \mathrm{NH}_{2}^{+}, \mathrm{NH}_{3}^{+}$, and $\mathrm{NH}_{4}^{+}$ions that, by dissociative recombinations, generate the formation of neutral nitrogen hydrides (see Fig. 1).

In addition, because the proton affinity of molecular nitrogen is $5.12 \mathrm{eV}$, the reaction of $\mathrm{N}_{2}$ with $\mathrm{H}_{3}^{+}$yielding $\mathrm{N}_{2} \mathrm{H}^{+}$is exothermic and proceeds at a significant rate. The DR of $\mathrm{N}_{2} \mathrm{H}^{+}$ then leads to NH. The formation of nitrogen hydrides has accordingly its origin in $\mathrm{N}_{2}$. On the other hand, nitriles (such as $\mathrm{HCN}$ ) derive from atomic nitrogen, through ion-neutral reactions with $\mathrm{CH}_{2}^{+}$and $\mathrm{CH}_{3}^{+}$. The formation of nitrogen hydrides is therefore a relatively slow process compared to carbon and oxygen hydrides, precisely because the first step involves the synthesis of molecular nitrogen, which is thought to proceed through neutral-neutral reactions (Pineau des Forêts et al. 1990; Hily-Blant et al. 2010b):

$$
\begin{aligned}
& \mathrm{N}+\mathrm{OH} \longrightarrow \mathrm{NO}+\mathrm{H} \\
& \mathrm{NO}+\mathrm{N} \longrightarrow \mathrm{N}_{2}+\mathrm{O} \\
& \text { and } \\
& \mathrm{N}+\mathrm{CH} \longrightarrow \mathrm{CN}+\mathrm{H} \\
& \mathrm{NO}+\mathrm{C} \longrightarrow \mathrm{CN}+\mathrm{O} \\
& \mathrm{CN}+\mathrm{N} \longrightarrow \mathrm{N}_{2}+\mathrm{C}
\end{aligned}
$$

We anticipate that in those instances where the $\mathrm{C} / \mathrm{O}$ gas-phase elemental abundance ratio is lower than unity, reaction (5) is expected to dominate the formation of $\mathrm{CN}$ over reaction (4).

Reaction (1) consequently appears to be a key reaction for the synthesis of nitrogen hydrides. In fact, it was studied in detail by Le Bourlot (1991), who derived separate rates for the reaction with ortho- and para- $\mathrm{H}_{2}$ (denoted $\mathrm{H}_{2}(\mathrm{o})$ and $\mathrm{H}_{2}(\mathrm{p})$, respectively, in the remainder of the text). The reaction with $\mathrm{H}_{2}(\mathrm{p})$ was assumed to occur with a $170 \mathrm{~K}$ activation energy, while being barrierless with $\mathrm{H}_{2}(\mathrm{o})$, which makes the rate of reaction (1) 
strongly dependent on the ortho-to-para ratio of $\mathrm{H}_{2}$ (denoted $\mathrm{o} / \mathrm{p}\left(\mathrm{H}_{2}\right)$ hereafter). More recently, Dislaire et al. (2012) have revised those rates (see Table B.1) using available experimental data (Marquette et al. 1988; Gerlich 1993) for $\mathrm{H}_{2}(\mathrm{p})$, normal- $\mathrm{H}_{2}$ (i.e. $\mathrm{o} / \mathrm{p}\left(\mathrm{H}_{2}\right)=3: 1$ ), and $\mathrm{H}_{2}(\mathrm{p})$ containing admixtures of $\mathrm{H}_{2}(\mathrm{o})$, leading to a rate at $10 \mathrm{~K}$ typically two orders of magnitude lower than in Le Bourlot (1991). In particular, for o/p $\left(\mathrm{H}_{2}\right) \lesssim 10^{-2}$, the new rate is below the critical value of $10^{-13} \mathrm{~cm}^{3} \mathrm{~s}^{-1}$ required to account for the observed amounts of gas-phase ammonia (Herbst et al. 1987). Nevertheless, Dislaire et al. (2012) could reproduce the abundance of ammonia observed towards IRAS 16293-2422, provided the total $\mathrm{C} / \mathrm{O}$ gas-phase abundance ratio was lower than 0.4. Recent measurements by Zymak et al. (2013) have confirmed the rate used by Dislaire et al. (2012), although issues related to the fine-structure relaxation of $\mathrm{N}^{+}$deserve further experimental and theoretical studies. Dislaire et al. (2012) also show that a branching ratio $<10 \%$ for the channel of $\mathrm{N}_{2} \mathrm{H}^{+}+\mathrm{e}^{-}$leading to $\mathrm{NH}$ is sufficient to reproduce the observed amount of $\mathrm{NH}$. The abundance of $\mathrm{NH}$ is thus independent of the o/p $\left(\mathrm{H}_{2}\right)$, unlike $\mathrm{NH}_{2}$ and $\mathrm{NH}_{3}$, which proceed from reaction (1). One consequence is that the $\mathrm{NH}: \mathrm{NH}_{2}$ abundance ratio depends on the $\mathrm{o} / \mathrm{p}\left(\mathrm{H}_{2}\right)$. Using the $\mathrm{NH}: \mathrm{NH}_{2}$ abundance ratio, Dislaire et al. (2012) could finally determine an $\mathrm{o} / \mathrm{p}\left(\mathrm{H}_{2}\right)$ of $\approx 10^{-3}$. However, these authors did not explicitly treat the formation of $\mathrm{H}_{2}(\mathrm{o})$ and $\mathrm{H}_{2}(\mathrm{p})$.

In the following, we discuss the new reaction rates that have been implemented to self-consistently model the formation of nitrogen hydrides of $\mathrm{H}_{2}(\mathrm{o})$ and $\mathrm{H}_{2}(\mathrm{p})$. This new network is an updated version of the gas-phase network of Flower et al. (2006a), as detailed below.

\subsection{The ortho-to-para ratio of $\mathrm{H}_{2}$}

The $\mathrm{o} / \mathrm{p}\left(\mathrm{H}_{2}\right)$ plays a significant role in the chemistry of nitrogen hydrides, making it important to understand the processes that may affect its value, in order to self-consistently model the chemistry. As $\mathrm{H}_{2}$ is not directly observable in the cold gas, its $\mathrm{o} / \mathrm{p}\left(\mathrm{H}_{2}\right)$ ratio derives from indirect measurements (e.g. Troscompt et al. 2009, and references therein). An upper limit of 0.01 has been proposed by Pagani et al. (2009) to explain the large deuteration fraction of $\mathrm{N}_{2} \mathrm{D}^{+}$in cold cores. Values consistent with this upper limit were predicted by the models of Flower et al. (2006b), with o/p $\left(\mathrm{H}_{2}\right) \approx 10^{-3}$. Molecular hydrogen is assumed to form on dust grain surfaces (Hollenbach \& Salpeter $1971)$, in a strongly exothermic reaction $(\approx 4.5 \mathrm{eV})$ such that the outcoming $\mathrm{H}_{2}(\mathrm{o})$ and $\mathrm{H}_{2}(\mathrm{p})$ should be in the ratio 3:1, imposed by their nuclear spin statistical weights. This corresponds to the maximum value permitted under thermal equilibrium. At temperatures lower than $100 \mathrm{~K}$, only the first rotational levels of $\mathrm{H}_{2}(\mathrm{p})$ and $\mathrm{H}_{2}(\mathrm{o})$ (lying $170.5 \mathrm{~K}$ above $\mathrm{H}_{2}(\mathrm{p})$ ) are populated significantly, and the equilibrium value of $\mathrm{o} / \mathrm{p}\left(\mathrm{H}_{2}\right)$ is given by the usual low-temperature approximation

$\mathrm{o} / \mathrm{p}\left(\mathrm{H}_{2}\right)=9 \exp (-170.5 / T)$

In the ISM, the characteristic timescale for radiative spontaneous spin flip from $J=1$ of $\mathrm{H}_{2}(\mathrm{o})$ to $J=0$ of $\mathrm{H}_{2}(\mathrm{p})$ is $\approx 10^{13} \mathrm{yr}$ (Raich \& Good 1964; Pachucki \& Komasa 2008), much longer than the lifetime of molecular clouds. As a consequence, the ortho and para forms may be viewed as two different chemical species, and gas-phase conversion from one form to the other is expected to take place only through ion-neutral reactions between $\mathrm{H}_{2}$ and protonated ions (Dalgarno et al. 1973; Crabtree et al. 2011). In a general fashion, these reactions can be written as

$\mathrm{H}_{2}(\mathrm{o})+\mathrm{XH}^{+} \rightarrow \mathrm{H}_{2}(\mathrm{p})+\mathrm{XH}^{+}$
$\mathrm{H}_{2}(\mathrm{p})+\mathrm{XH}^{+} \rightarrow \mathrm{H}_{2}(\mathrm{o})+\mathrm{XH}^{+}$

where $\mathrm{XH}^{+}$stands primarily for $\mathrm{H}^{+}, \mathrm{H}_{3}^{+}$, and $\mathrm{HCO}^{+}$. If both exchange reactions proceed much more rapidly than the formation of $\mathrm{H}_{2}$ on grains, the $\mathrm{o} / \mathrm{p}\left(\mathrm{H}_{2}\right)$ is expected to tend towards a value imposed by the detailed balance relation between the rates of reactions (8)-(9) that is the thermal value of Eq. (7). In contrast, if the formation rate on dust grains is much faster than any of the two exchange reactions, the $\mathrm{o} / \mathrm{p}\left(\mathrm{H}_{2}\right)$ value will stay equal to $3: 1$. As said previously, there is some evidence that the $\mathrm{o} / \mathrm{p}$ of $\mathrm{H}_{2}$ significantly deviates from both $3: 1$ and the thermodynamical value of $\approx 3 \times 10^{-7}$ at $10 \mathrm{~K}$. This indicates that certain conversion processes do take place on timescales comparable to or even shorter than the formation process on dust grains.

The gas-phase conversion between $\mathrm{H}_{2}(\mathrm{o})$ and $\mathrm{H}_{2}(\mathrm{p})$ has received particular attention in the past few years. We have therefore adopted the most recent theoretical results summarised in Table B.1. In particular, the conversion through reactions with protons has been computed by Honvault et al. (2011, 2012) using state-to-state quantum time-independent calculations. Exchange reactions with $\mathrm{H}_{3}^{+}$have been studied using a state-to-state microcanonical statistical method by Hugo et al. (2009). The $\mathrm{H}_{3}^{+}+$ $\mathrm{H}_{2}$ reaction was also studied experimentally below $100 \mathrm{~K}$ by Grussie et al. (2012), confirming the micro-canonical model. The rates of Hugo et al. (2009) are available for temperatures below $50 \mathrm{~K}$, restricting the validity of our network to this lowtemperature range.

In addition to the formation of $\mathrm{H}_{2}$ on grains and to the orthoto-para exchange reactions between $\mathrm{H}_{2}$ and protonated ions, the formation and destruction of the $\mathrm{H}_{3}^{+}$ion also play an important role in setting the $\mathrm{o} / \mathrm{p}\left(\mathrm{H}_{2}\right)$ value. We have therefore updated the rate coefficients and branching ratios for the reaction $\mathrm{H}_{2}^{+}+\mathrm{H}_{2}$ and the dissociative recombination $\mathrm{H}_{3}^{+}+\mathrm{e}^{-}$. To this aim, we have combined the most recent theoretical and experimental values of the overall rate coefficients with the Oka's formalism (Oka 2004) to derive the nuclear spin branching ratios. Briefly, this formalism accounts for the selection rules that result from conserving the nuclear spin of identical nuclei. The approach of Oka (2004) is based on angular momentum algebra applied to the total nuclear spins of the reactants. For each allowed nuclear spin of the intermediate complex, the distribution of product states is deduced from the nuclear-spin conservation for the reverse reaction. Full details can be found in Oka (2004). It should be noted that these pure nuclear spin branching ratios are applicable to processes in which many rotational states of the products are populated, in particular exothermic reactions. In this work, these branching ratios were used for strongly exothermic ion-molecule and DR reactions where the products are expected to form rotationally hot, along with full proton scrambling. The corresponding new rate coefficients are listed in Tables B.1 and B.2. We note that most measurements have no temperature dependence since they were only performed at room temperature.

Very recently, Faure et al. (2013) have shown that these new rates do not significantly change the $\mathrm{o} / \mathrm{p}\left(\mathrm{H}_{2}\right)$ at steady state with respect to the results of Flower et al. (2006b). A constant o/p $\left(\mathrm{H}_{2}\right)$ of $\sim 10^{-3}$ was thus found below $15 \mathrm{~K}$. Above this temperature, the $\mathrm{o} / \mathrm{p}\left(\mathrm{H}_{2}\right)$ was shown to converge towards the thermal value, as expected from the competition between the $\mathrm{H}_{2}$ formation on grains and the exchange reactions with protonated ions. This point will be further discussed elsewhere. 


\subsection{Atomic to molecular nitrogen conversion}

As previously mentioned in Sect. 2.1, the atomic-to-molecular conversion is the first step towards synthesis of nitrogen hydrides in dark clouds. The rates of reactions (2)-(6) have been uncertain at low temperatures, and in particular the existence of low activation energy $(\approx 20 \mathrm{~K})$ has been suggested by the CN:NO abundance ratio (Akyilmaz et al. 2007). The rates for the $\mathrm{NO}+\mathrm{N}$ and $\mathrm{CN}+\mathrm{N}$ reactions have been revisited experimentally by Daranlot et al. $(2011,2012)$ using the CRESU technique down to temperatures of $\approx 50 \mathrm{~K}$ and further extrapolated down to $10 \mathrm{~K}$. The new rates implemented in our network are summarised in Table B.3. We note that these rates present positive and negative temperature dependences (see Table B.3) and that they all lie between $4 \times 10^{-12} \mathrm{~cm}^{3} \mathrm{~s}^{-1}$ and $2 \times 10^{-10} \mathrm{~cm}^{3} \mathrm{~s}^{-1}$ at $10 \mathrm{~K}$. These radical-neutral reactions are therefore moderately fast, but they provide the main routes in converting $\mathrm{N}$ to $\mathrm{N}_{2}$. The typical chemical timescales of nitrogen chemistry are discussed below.

\subsection{Nitrogen hydrides synthesis}

As previously emphasised, the $\mathrm{o} / \mathrm{p}\left(\mathrm{H}_{2}\right)$ has a strong effect on the chemistry of nitrogen hydrides. To take the $\mathrm{o} / \mathrm{p}\left(\mathrm{H}_{2}\right)$ into account self-consistently, some care must be taken in the dissociative recombinations of ionic nitrogen hydrides, $\mathrm{NH}_{\mathrm{n}}^{+}+\mathrm{e}^{-}$ $(n=3,4)$, since these reactions produce $\mathrm{H}_{2}(\mathrm{o})$ and $\mathrm{H}_{2}(\mathrm{p})$, in amounts that depend on the nuclear spin branching ratios. The associated hydrogen abstractions $\mathrm{NH}_{\mathrm{n}}^{+}+\mathrm{H}_{2}(n=0-3)$ are also crucial in driving the nuclear spin distributions. The corresponding branching ratios were determined by Rist et al. (2013) using Oka's formalism discussed above and assuming full scrambling. These branching ratios were found to be significantly different from those derived by Flower et al. (2006a). In this pioneering study, where the conservation of the total nuclear spin angular momentum was included, the branching ratios were indeed derived from simple statistical considerations without recourse to the angular momentum rules of Oka (2004; see also Sipilä et al. 2013 , for a recent similar work). The new branching ratios derived by Rist et al. (2013) were employed very recently by Faure et al. (2013) in their work on the o/p of ammonia in the cold interstellar gas.

It should be noted that interconversion processes between the nuclear states of ionic hydrides, of the form $\mathrm{NH}_{\mathrm{n}}^{+}+$ $\mathrm{H}_{2} \longrightarrow \mathrm{NH}_{\mathrm{n}}^{+}+\mathrm{H}_{2}(n=2-4)$, are ignored in this work. Indeed, these proton scrambling reactions were studied experimentally using deuterated analogues, and H-D exchanges were not observed, setting small upper limits for the rate coefficients (see the discussion in Faure et al. 2013). In addition, Faure et al. (2013) explicitly studied the $\mathrm{NH}_{4}^{+}+\mathrm{H}_{2} \longrightarrow \mathrm{NH}_{4}^{+}+\mathrm{H}_{2}$ thermalisation reaction and showed that this reaction must be negligible in order to explain the observed non-thermal o/p of $\mathrm{NH}_{3}(\sim 0.7)$. Crucial, too, is the branching ratio of the DR of $\mathrm{N}_{2} \mathrm{H}^{+}$. As emphasised by Dislaire et al. (2012), the channel leading to $\mathrm{NH}$ was pivotal in explaining the observed $\mathrm{NH}: \mathrm{NH}_{2}$ ratio that is greater than unity. These authors show that a branching ratio lower than $10 \%$ is sufficient, and recent storage ring measurements by Vigren et al. (2012) confirm this value, with a branching ratio of $7_{-4}^{+2} \%$. Branching ratios for the DR of the $\mathrm{NH}_{\mathrm{n}}^{+}(n=2-4)$ ions are taken from Mitchell (1990), Thomas et al. (2005), Jensen et al. (2000), and Öjekull et al. (2004) (see Table B.2), following Hily-Blant et al. (2010a).

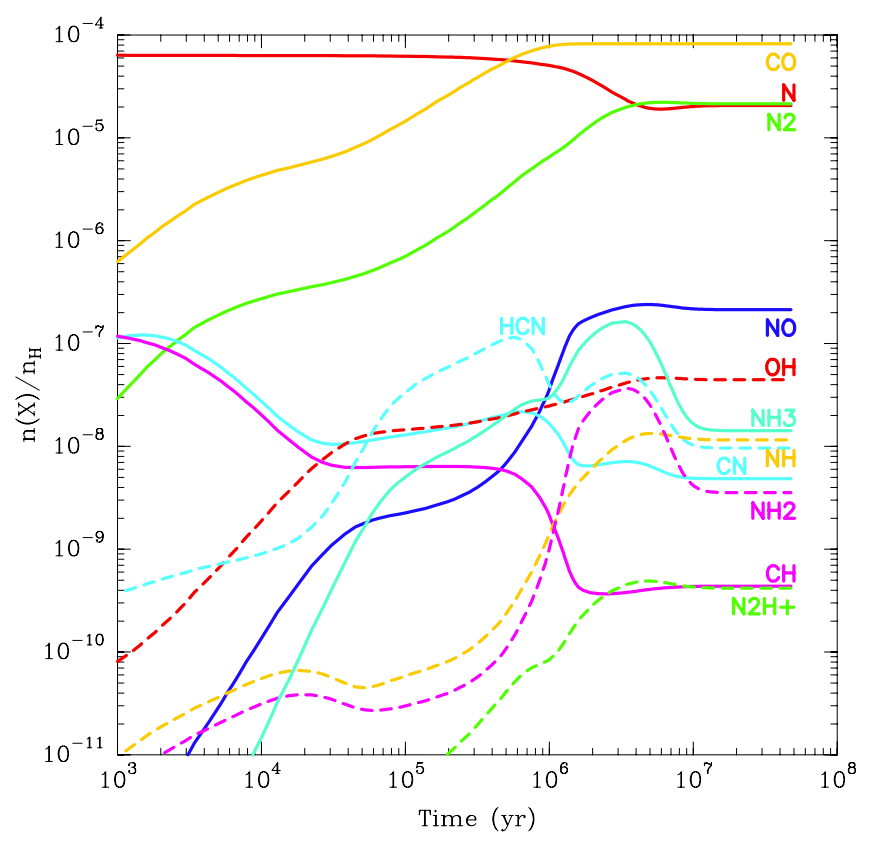

Fig. 2. Time evolution of the abundances of the main nitrogenated species and species involved in the $\mathrm{N}-$ to- $\mathrm{N}_{2}$ conversion. For this particular model (our best model), the total gas-phase abundance ratio $\mathrm{C} / \mathrm{O}$ is 0.8 and the total gas-phase abundance of sulphur is $8.0 \times 10^{-8}$.

We summarise, in Tables B.1-B.3, all the updates and improvements from the Flower et al. network, including the orthoand para-forms of hydrogen and nitrogen species ${ }^{1}$.

\section{Modelling}

\subsection{General description}

The complete network contains 104 species (see Table 1) and 917 reactions. The physical conditions, which are fixed, are typical of dark clouds: the gas has a constant number density of hydrogen nuclei $n_{\mathrm{H}}=n(\mathrm{H})+2 n\left(\mathrm{H}_{2}\right)$ of $10^{4} \mathrm{~cm}^{-3}$, shielded from the UV photons by ten magnitudes of visual extinction, and the kinetic temperature is kept constant at $10 \mathrm{~K}$. Ionisation is driven by cosmic rays, with secondary photons included, and the ionisation rate of hydrogen is $\zeta=1.3 \times 10^{-17} \mathrm{~s}^{-1}$, a standard value usually attributed to dense regions (Prasad \& Huntress 1980; Caselli et al. 1998; Wakelam et al. 2005). The processes involving dust grains are charge exchange, DR reactions, and the formation of $\mathrm{H}_{2}$. We adopt a single dust grain radius of $0.1 \mu \mathrm{m}$, following Walmsley et al. (2004), satisfying a dust-to-gas mass ratio of $1 \%$. The abundances of all species are followed with time, until a steady state is reached. A typical illustrative result is shown in Fig. 2.

Even though we compute the time evolution of all the abundances, we focus our analysis on the steady state, which is reached typically after $\sim 1$ Myr for carbon- and oxygen-bearing species, 3-5 Myr for NO, $\mathrm{N}_{2} \mathrm{H}^{+}$, and $\mathrm{NH}$, and after $\sim 10 \mathrm{Myr}$ for nitrogen-bearing species (see Fig. 2). We note that these timescales are probably upper limits since they correspond to initial conditions where all elements (except hydrogen) are in atomic form. As mentioned earlier, nitrogen hydrides are latetime species, a consequence of the slow neutral-neutral reactions needed to build $\mathrm{N}_{2}$. The timescale of $10 \mathrm{Myr}$ is longer than

1 The full chemical network is available on request to pierre. hily-blant@obs.ujf-grenoble.fr 
Table 1. The 104 gas-phase chemical species considered in our network.

\begin{tabular}{ccccccccccccccc}
\hline \hline $\mathrm{H}$ & $\mathrm{H}_{2}(\mathrm{p})$ & $\mathrm{H}_{2}(\mathrm{o})$ & $\mathrm{He}$ & $\mathrm{C}$ & $\mathrm{CH}$ & $\mathrm{CH}_{2}$ & $\mathrm{CH}_{3}$ & $\mathrm{CH}_{4}$ & $\mathrm{O}$ & $\mathrm{O}_{2}$ & $\mathrm{OH}$ & $\mathrm{H}_{2} \mathrm{O}$ & $\mathrm{CO}$ \\
$\mathrm{CO}_{2}$ & $\mathrm{C}_{2}$ & $\mathrm{C}_{2} \mathrm{H}$ & $\mathrm{C}_{2} \mathrm{H}_{2}$ & $\mathrm{C}_{3}$ & $\mathrm{C}_{3} \mathrm{H}$ & $\mathrm{C}_{3} \mathrm{H}_{2}$ & $\mathrm{CH}_{3} \mathrm{OH}$ & $\mathrm{H}_{2} \mathrm{CO}$ & $\mathrm{HCO}_{2} \mathrm{H}$ & $\mathrm{N}$ & $\mathrm{NH}$ & $\mathrm{NH}_{2}(\mathrm{p})$ & $\mathrm{NH}_{2}(\mathrm{o})$ \\
$\mathrm{NH}_{3}(\mathrm{p})$ & $\mathrm{NH}_{3}(\mathrm{o})$ & $\mathrm{CN}$ & $\mathrm{HCN}$ & $\mathrm{HNC}$ & $\mathrm{N}_{2}$ & $\mathrm{NO}$ & $\mathrm{S}$ & $\mathrm{SH}$ & $\mathrm{H}_{2} \mathrm{~S}$ & $\mathrm{CS}$ & $\mathrm{SO}$ & $\mathrm{SO}_{2}$ & $\mathrm{OCS}^{2}$ \\
$\mathrm{Mg}$ & $\mathrm{Fe}$ & $\mathrm{H}^{+}$ & $\mathrm{H}_{2}^{+}(\mathrm{p})$ & $\mathrm{H}_{2}^{+}(\mathrm{o})$ & $\mathrm{H}_{3}^{+}(\mathrm{p})$ & $\mathrm{H}_{3}^{+}(\mathrm{o})$ & $\mathrm{He}^{+}$ & $\mathrm{C}^{+}$ & $\mathrm{CH}^{+}$ & $\mathrm{CH}_{2}^{+}$ & $\mathrm{CH}_{3}^{+}$ & $\mathrm{CH}_{4}^{+}$ & $\mathrm{CH}_{5}^{+}$ \\
$\mathrm{O}^{+}$ & $\mathrm{O}_{2}^{+}$ & $\mathrm{OH}^{+}$ & $\mathrm{OD}^{+}$ & $\mathrm{H}_{2} \mathrm{O}^{+}$ & $\mathrm{H}_{3} \mathrm{O}^{+}$ & $\mathrm{CO}^{+}$ & $\mathrm{HCO}^{+}$ & $\mathrm{HCO}_{2}^{+}$ & $\mathrm{C}_{2}^{+}$ & $\mathrm{C}_{2} \mathrm{H}^{+}$ & $\mathrm{C}_{2} \mathrm{H}_{2}^{+}$ & $\mathrm{C}_{2} \mathrm{H}_{3}^{+}$ & $\mathrm{C}_{3}^{+}$ \\
$\mathrm{C}_{3} \mathrm{H}^{+}$ & $\mathrm{C}_{3} \mathrm{H}_{2}^{+}$ & $\mathrm{C}_{3} \mathrm{H}_{3}^{+}$ & $\mathrm{N}^{+}$ & $\mathrm{NH}^{+}$ & $\mathrm{NH}_{2}^{+}(\mathrm{p})$ & $\mathrm{NH}_{2}^{+}(\mathrm{o})$ & $\mathrm{NH}_{3}^{+}(\mathrm{p})$ & $\mathrm{NH}_{3}^{+}(\mathrm{o})$ & $\mathrm{NH}_{4}^{+}(\mathrm{p})$ & $\mathrm{NH}_{4}^{+}(\mathrm{m})$ & $\mathrm{NH}_{4}^{+}(\mathrm{o})$ & $\mathrm{CN}^{+}$ & $\mathrm{C}_{2} \mathrm{~N}^{+}$ \\
$\mathrm{HCN}^{+}$ & $\mathrm{H}_{2} \mathrm{CN}^{+}$ & $\mathrm{H}_{2} \mathrm{NC}^{+}$ & $\mathrm{N}_{2}^{+}$ & $\mathrm{N}_{2} \mathrm{H}^{+}$ & $\mathrm{NO}^{+}$ & $\mathrm{HNO}^{+}$ & $\mathrm{S}^{+}$ & $\mathrm{SH}^{+}$ & $\mathrm{H}_{2} \mathrm{~S}^{+}$ & $\mathrm{H}_{3} \mathrm{~S}^{+}$ & $\mathrm{CS}^{+}$ & $\mathrm{HCS}^{+}$ & $\mathrm{SO}^{+}$ \\
$\mathrm{HSO}^{+}$ & $\mathrm{HSO}_{2}^{+}$ & $\mathrm{HOCS}^{+}$ & $\mathrm{Fe}^{+}$ & $\mathrm{C}_{4} \mathrm{H}^{+}$ & $\mathrm{C}_{6} \mathrm{H}^{+}$ & & & & & & & & & \\
\hline
\end{tabular}

Notes. (o), (p), and (m) stand for ortho, para, and meta states respectively.

the gravitational free-fall timescale of $\sim 0.5$ Myr but comparable to the ambipolar diffusion timescale of $\sim 10$ Myr at a density of $10^{4} \mathrm{~cm}^{-3}$ (Tassis \& Mouschovias 2004; Bergin \& Tafalla 2007). Indeed, in their chemical models of collapsing cores, Tassis et al. (2012) also considered delay times (before collapse starts) up to $10 \mathrm{Myr}$.

Another assumption of our model is that freeze-out, which occurs on a typical timescale of $\sim 10^{10} / n_{\mathrm{H}}$ yr (Bergin \& Tafalla 2007), is not considered during the time evolution of the gas, although observations show depletion of several species in prestellar cores (e.g. Tafalla et al. 2004). However, observations also show that an important fraction of molecular species remains in the gas phase, such that desorption mechanisms are required (Hasegawa \& Herbst 1993). Those are highly uncertain and depend critically on binding energies of the adsorbed species. Nevertheless, molecular mantles are observed in the core of dense dark clouds (Whittet et al. 1983; Boogert et al. 2011), indicating that molecular condensation on grains occurs efficiently. This effect is crudely accounted for in our model by adopting initially depleted elemental abundances in the gas phase. We also note that although steady state is rather unlikely, both steadystate and time-dependent modelling have their own limitations. Time-dependent calculations depend critically on the assumed initial abundances, which are poorly known, whilst steady-state models do not. In addition, focussing on the steady state does not prevent identifying key reactions and general trends, while avoiding the uncertainties described above.

\subsection{Elemental abundances}

The choice of the gas-phase elemental abundances is not a trivial task, nonetheless, and the abundances of the elements strongly influence the chemical state of the gas. One example is the relative amount of carbon and oxygen, which is known to strongly affect the chemistry (van Dishoeck \& Blake 1998; Le Bourlot et al. 1995). For most of the elements, including nitrogen, we follow Flower et al. (2005), who have estimated gas-phase elemental abundances by combining observational constraints from the diffuse ISM and infrared signatures of ices (Gibb et al. 2000), and assuming the composition for the refractory core of dust grains. Nevertheless, the abundances of carbon, oxygen, and sulphur deserve special attention.

The elemental gas-phase abundance of sulphur, noted $[\mathrm{S}]_{\text {tot }}$, is very poorly constrained. It can vary by almost three orders of magnitude if we consider the range delimited by the socalled low metal abundance and high metal abundance cases defined originally by Graedel et al. (1982). The first category is suggested by the low electron abundance in dense clouds and may be more representative of the chemistry in such environments, whilst the second category reflects the standard $\zeta$ Oph sightline. Further studies of dense dark clouds have corroborated the low metal sulphur gas-phase abundance, even where elemental carbon, oxygen, and nitrogen are depleted by only factors of a few (Ruffle et al. 1999). In the well studied TMC-1 and L183 dark clouds, Tieftrunk et al. (1994) found that the sum of all detected S-bearing molecules represents only $0.1 \%$ of the elemental sulphur solar abundance $[\mathrm{S}]_{\text {tot }} \approx 1.5 \times 10^{-5}$ (Przybilla et al. 2008; Asplund et al. 2009). In the following, we have applied depletion factors from the gas phase of 200, 20, and 2, or abundances with respect to $\mathrm{H}$ nuclei of $8.0 \times 10^{-8}, 8.0 \times 10^{-7}$, and $8.0 \times 10^{-6}$, respectively.

The reference cosmic abundance for oxygen is $575 \mathrm{ppm}$ (Przybilla et al. 2008). Based on 56 diffuse sightlines, Cartledge et al. (2004) have shown that the gas-phase abundance of oxygen decreases with increasing sightline mean density, reflecting the uptake of oxygen in silicate and oxides into grain cores. They found an average gas-phase atomic oxygen abundance of $280 \mathrm{ppm}$ for densities greater than $1.5 \mathrm{~cm}^{-3}$, suggesting that up to $300 \mathrm{ppm}$ of oxygen have been removed from the gas phase. This idea has been further developed by Whittet (2010), who performed a comprehensive oxygen budget up to densities $\sim 1000 \mathrm{~cm}^{-3}$, and shows that $\sim 100 \mathrm{ppm}$ and $\sim 120 \mathrm{ppm}$ are locked into ices and silicates or oxydes, respectively. Taking into account that $\sim 50 \mathrm{ppm}$ is in gaseous $\mathrm{CO}$, it must be recognised that up to $\sim 300 \mathrm{ppm}$ of oxygen are in unknown carriers. The depletion of oxygen not accounted for by known carriers is also demonstrated by Nieva \& Przybilla (2012) who compared the abundances derived by Cartledge et al. with their Cosmic Abundance Standard based on B-stars.

Depletion of carbon is surprisingly not well constrained (see e.g. Fig. 5 of Jenkins 2009), essentially for observational limitations. In addition, the column densities derived so far in the literature may overestimate the amount of gas-phase carbon, because of an underestimated oscillator strength for the CII transition at $2325 \AA$ (Sofia et al. 2011). The error could be up to a factor of two.

To reflect the large uncertainties in the gas-phase elemental abundances of carbon and oxygen, we decided to vary the carbon-to-oxygen gas-phase elemental abundance ratio, $[\mathrm{C}]_{\text {tot }} /[\mathrm{O}]_{\text {tot }}$, simply noted $\mathrm{C} / \mathrm{O}$ hereafter. To do so, we have assumed a constant elemental abundance of carbon, $[\mathrm{C}]_{\text {tot }}=$ $8.3 \times 10^{-5}$, and varied that of oxygen from $50 \mathrm{ppm}$ to $280 \mathrm{ppm}$. The lower limit is imposed by gaseous CO, and the upper limit is taken from Cartledge et al. (2004). The corresponding range in $\mathrm{C} / \mathrm{O}$ is 0.3 to 1.5 . The upper value of $280 \mathrm{ppm}$ implicitely requires that $\sim 230 \mathrm{ppm}$ of oxygen have been taken from the 
Table 2. Gas-phase elemental abundances ${ }^{a}$ adopted in our model.

\begin{tabular}{lrr}
\hline \hline Element & This work & Flower et al. (2005) \\
\hline $\mathrm{He}$ & 0.10 & 0.10 \\
$\mathrm{C}^{b}$ & $8.3(-5)$ & $8.3(-5)$ \\
$\mathrm{N}^{b}$ & $6.4(-5)$ & $6.4(-5)$ \\
$\mathrm{O}$ & $5.5(-5)$ to $2.8(-4)$ & $1.2(-4)$ \\
$\mathrm{S}^{c}$ & $8.0(-8)$ to $8.0(-6)$ & $6.0(-7)$ \\
$\mathrm{Fe}^{b}$ & $1.5(-9)$ & $1.5(-9)$ \\
\hline
\end{tabular}

Notes. ${ }^{(a)}$ Fractional abundances relative to total H nuclei. Numbers in parentheses are powers of $10 .^{(b)}$ The elemental abundances of gasphase nitrogen, carbon, and iron are taken from Flower et al. (2005).

(c) The lower value of the total gas-phase elemental abundance of $\mathrm{S}$ is taken from the "low metal" case of Graedel et al. (1982).

various reservoirs (solid, ices, unknown carriers) and released in the gas phase by some unspecified processes. Our strategy is therefore analogous in some respects to the one adopted by Terzieva \& Herbst (1998) and Tassis et al. (2012), who considered a similar range of elemental $\mathrm{C} / \mathrm{O}$ ratios. However, the main difference with our model is that we do not consider gasgrain processes apart from charge exchange with grains and $\mathrm{H}_{2}$ formation, such that the total amount of gas-phase carbon and oxygen remain constant during the time evolution. For each value of $\mathrm{C} / \mathrm{O}$, three models, corresponding to the three sulphur abundances discussed above, were performed. The initial gasphase elemental abundances are summarised in Table 2.

\section{Results}

\subsection{Influence of the $\mathrm{C} / \mathrm{O}$ ratio}

The steady-state abundances of several nitrogenated species, together with chemically related species, are shown in Fig. 3, as a function of the elemental $\mathrm{C} / \mathrm{O}$ gas-phase abundance ratio, for three sulphur abundances. We first focus on the low metal sulphur abundance (left panel). For all values of $\mathrm{C} / \mathrm{O}$, atomic and molecular nitrogen are the most abundant species, except at high $\mathrm{C} / \mathrm{O}$, where $\mathrm{CN}$ becomes more abundant than N. Our model predicts that, at low and high $\mathrm{C} / \mathrm{O}$, molecular nitrogen is the dominant carrier of nitrogen. Oxygen-bearing species such as $\mathrm{NO}$ and $\mathrm{OH}$ see their abundance decreasing with increasing $\mathrm{C} / \mathrm{O}$, by 2 to 5 orders of magnitude. This is a consequence of the decreasing total amount of oxygen available in the gas-phase. In contrast, the abundances of $\mathrm{CN}$ and $\mathrm{CH}$ increase by the same amount. Nevertheless, for the latter species, this is not due to an increase in the total amount of carbon, but to an increase in the amount of carbon available in the gas phase, since less carbon is locked into the very stable $\mathrm{CO}$ molecule. The turning point between the low- and high-C/O regimes occurs around 0.9 . In this intermediate regime $(0.8 \leq \mathrm{C} / \mathrm{O} \leq 1.0)$, molecular nitrogen is no longer the main reservoir of nitrogen because $\mathrm{OH}$ and $\mathrm{CH}$, which ensure the conversion from $\mathrm{N}$ to $\mathrm{N}_{2}$, are two orders of magnitude less abundant. The above reasoning remains true for a total gasphase sulphur abundance of $8.0 \times 10^{-7}$, although the mid-C/O regime now extends up to 1.1. At an even higher total gas-phase abundance of sulphur, the high-C/O regime in which $\mathrm{N}: \mathrm{N}_{2}<1$ is not recovered.

The evolution of nitrogen hydrides with $\mathrm{C} / \mathrm{O}$ is not uniform. For sulphur abundances up to $8.0 \times 10^{-7}$, the NH abundance varies by less than an order of magnitude over the whole range of the $\mathrm{C} / \mathrm{O}$ ratio, in sharp contrast with $\mathrm{NH}_{2}$ whose abundance decreases from $10^{-8}$ in the low-C/O regime to $10^{-10}$ in the high$\mathrm{C} / \mathrm{O}$ regime. The abundance of ammonia is a few $10^{-8}$ in both the low- and high-C/O regimes, but drops to $10^{-9}$ in the mid$\mathrm{C} / \mathrm{O}$ regime. When $[\mathrm{S}]_{\text {tot }}=8.0 \times 10^{-6}$, the behaviour of $[\mathrm{NH}]$ is similar to that of $\left[\mathrm{NH}_{2}\right]$, and drops by more than an order of magnitude from the low- to high- $\mathrm{C} / \mathrm{O}$ regimes. For ammonia, the same trend holds, but unlike $[\mathrm{NH}]$ or $\left[\mathrm{NH}_{2}\right],\left[\mathrm{NH}_{3}\right]$ manages to increase with $\mathrm{C} / \mathrm{O}$, although not recovering its value of the low$\mathrm{C} / \mathrm{O}$ regime.

We here provide explanations for the observed abundance behaviours, focussing on the low metal sulphur abundance case. The evolution with $\mathrm{C} / \mathrm{O}$ of the balance between $\mathrm{N}$ and $\mathrm{N}_{2}$ is explained by the fact that as $\mathrm{C} / \mathrm{O}$ increases, more oxygen and less carbon - relative to the total - are locked into $\mathrm{CO}$. Therefore, there is less oxygen available in the gas phase, and the abundances of $\mathrm{NO}$ and $\mathrm{OH}$ drop. The contrary holds true for carbon: there is more $\mathrm{CH}$ and $\mathrm{CN}$. Since the $\mathrm{N}$-to- $\mathrm{N}_{2}$ conversion proceeds through $\mathrm{NO}$ and/or $\mathrm{CN}$, this explains the peak of $\mathrm{N}: \mathrm{N}_{2}$ ratio for $\mathrm{C} / \mathrm{O} \sim 1$. As a consequence, the modelled abundances of all nitrogen hydrides, which strongly depend on the conversion of $\mathrm{N}$ into $\mathrm{N}_{2}$, decrease at $\mathrm{C} / \mathrm{O} \sim 1$. However, that ammonia recovers its low-C/O abundance at high $\mathrm{C} / \mathrm{O}$, when $\mathrm{NH}$ and $\mathrm{NH}_{2}$ do not, stems from the fact that these two radicals are primarily destroyed by reactions with atomic carbon, while ammonia is not. Reaction of $\mathrm{NH}$ with neutral carbon forms $\mathrm{CN}$, and $\mathrm{NH}_{2}+\mathrm{C}$ produces $\mathrm{HCN}$ and $\mathrm{HNC}$. On the other hand, $\mathrm{NH}_{3}$ is not destroyed by neutral carbon but by $\mathrm{H}_{3}^{+}$(whose abundance does not strongly depend on $\mathrm{C} / \mathrm{O}), \mathrm{HCO}^{+}$, and $\mathrm{C}^{+}$. As a consequence, in the high$\mathrm{C} / \mathrm{O}$ regime, the large amount of carbon not locked into $\mathrm{CO}$ enhances mostly the destruction of $\mathrm{NH}$ and $\mathrm{NH}_{2}$. At the same time, the $\mathrm{N}$-to- $\mathrm{N}_{2}$ conversion restarts through $\mathrm{CN}$, and the formation of ammonia increases.

\subsection{Influence of the sulphur abundance}

We now further analyse the influence of the total sulphur abundance on the steady-state abundances of nitrogen hydrides. As shown in the top panels of Fig. 3, models with $[\mathrm{S}]_{\text {tot }}=$ $8.0 \times 10^{-8}$ and $8.0 \times 10^{-7}$ are very similar, and the only change is the broadening of the mid- $\mathrm{C} / \mathrm{O}$ regime mentioned above. For $[\mathrm{S}]_{\text {tot }}=8.0 \times 10^{-6}, \mathrm{CN}$ and $\mathrm{CH}$ abundances drop by more than an order of magnitude at high $\mathrm{C} / \mathrm{O}$, whereas those of $\mathrm{NO}$ and $\mathrm{OH}$ increase.

The broadening of the mid-C/O regime as $[\mathrm{S}]_{\text {tot }}$ increases results from a combination of several chemical effects. As already mentioned, in this regime, characterised by $\mathrm{N}: \mathrm{N}_{2}>1$, the conversion from $\mathrm{N}$ to $\mathrm{N}_{2}$ is weak, because of the low abundances of $\mathrm{CH}$ and $\mathrm{OH}$. Comparing models with $[\mathrm{S}]_{\text {tot }}=8.0 \times 10^{-7}$ and $8.0 \times 10^{-6},[\mathrm{CH}]$ drops by about two orders of magnitude at high $\mathrm{C} / \mathrm{O}$, while $[\mathrm{OH}]$ is only marginally affected. Although [NO] increases by more than a factor 10 , it remains 100 times less abundant than $\mathrm{CN}$ and does not compensate for the drop of $[\mathrm{CN}]$. The net effect is a global decrease of the conversion partners. As a result, $\mathrm{N}$ remains more abundant than $\mathrm{N}_{2}$ up to $\mathrm{C} / \mathrm{O}=1.5$. Thus, the effect of $[\mathrm{S}]_{\text {tot }}$ must be traced back to $\mathrm{CH}$, through the reaction

$\mathrm{S}^{+}+\mathrm{CH} \longrightarrow \mathrm{CS}^{+}+\mathrm{H}$

which removes $\mathrm{CH}$. A similar reaction holds for $\mathrm{OH}$, but its abundance decreases only slightly. To understand this behaviour, we notice that $\mathrm{OH}$ is formed through the $\mathrm{DR}$ of $\mathrm{H}_{3} \mathrm{O}^{+}$, the abundance of which decreases with $[\mathrm{S}]_{\text {tot }}$. Indeed the ionisation potential of $\mathrm{S}(10.36 \mathrm{eV})$ is lower than that of $\mathrm{H}$, and increasing 

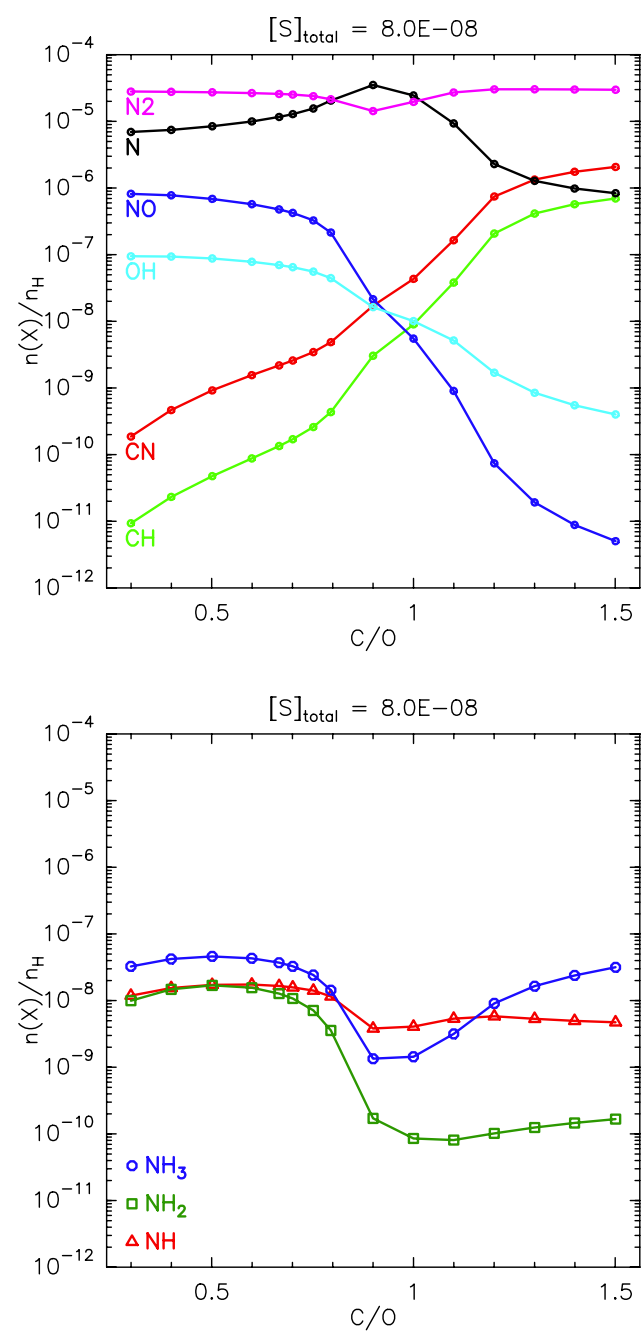

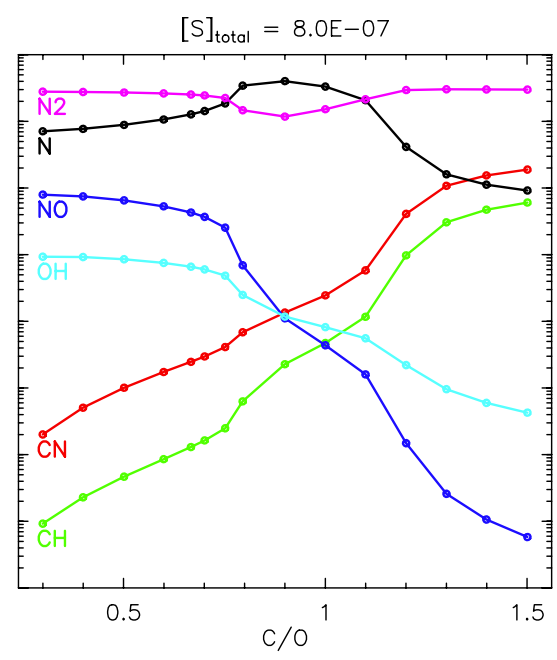

$[\mathrm{S}]_{\text {total }}=8.0 \mathrm{E}-07$

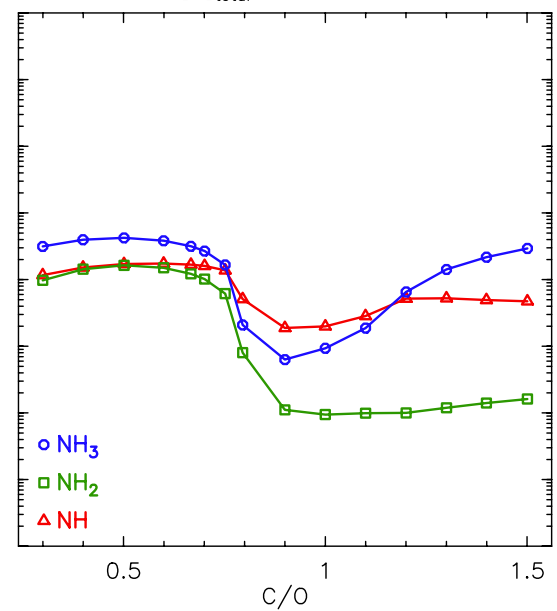

$[\mathrm{S}]_{\mathrm{total}}=8.0 \mathrm{E}-06$

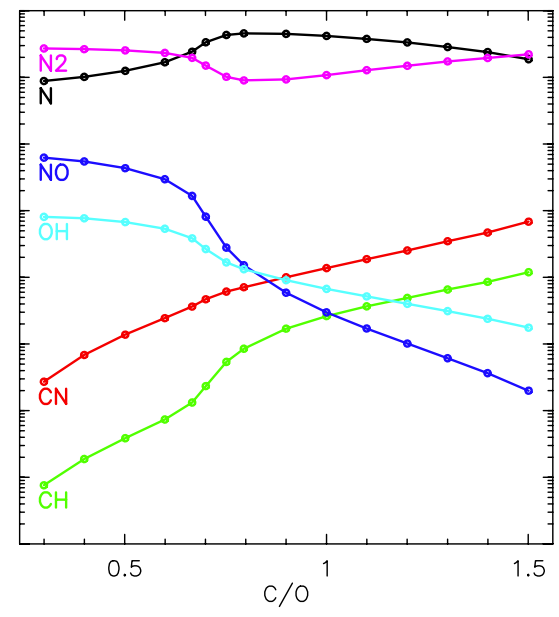

$[\mathrm{S}]_{\mathrm{total}}=8.0 \mathrm{E}-06$

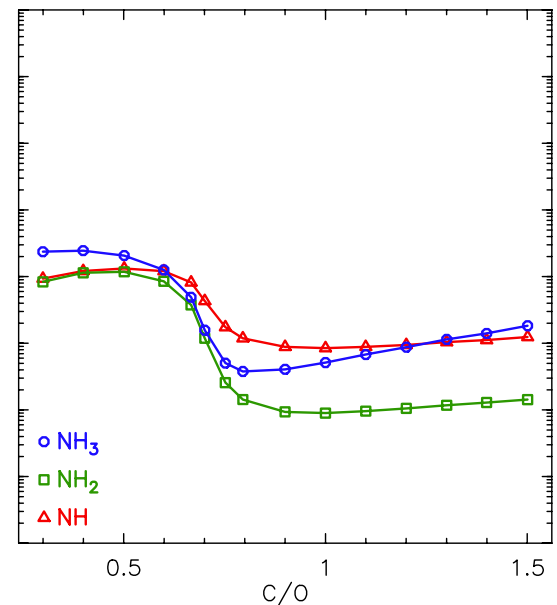

Fig. 3. Steady-state abundances of several nitrogen-bearing and nitrogen-chemistry related species, as a function of the gas-phase elemental abundance ratio of $\mathrm{C} / \mathrm{O}$, for three different values of gas-phase elemental abundance of sulphur (from left to right: $[\mathrm{S}]_{\mathrm{tot}}=8.0 \times 10^{-8}, 8.0 \times 10^{-7}$, $\left.8.0 \times 10^{-6}\right) . \mathrm{C} / \mathrm{O}$ values include $0.3,0.4,0.5,0.6,0.7,0.75,0.8,0.9,1.0,1.1,1.2,1.3,1.4,1.5$, and 0.67 , which was the ratio employed in the previous studies of Flower et al. 2006. Top panels: molecules involved in the atomic-to-molecular conversion of nitrogen. Bottom panels: nitrogen hydrides.

$[\mathrm{S}]_{\text {tot }}$ drives up the ionisation fraction. The resulting enhanced DR destruction of $\mathrm{H}_{3} \mathrm{O}^{+}$thus compensates for the destruction of $\mathrm{OH}$ by $\mathrm{S}^{+}$. In the mid-C/O regime at low-to-intermediate sulphur abundances, there is such a combination of effects that both $\mathrm{OH}$ and $\mathrm{CH}$ remain too rare to ensure an efficient conversion of $\mathrm{N}$ into $\mathrm{N}_{2}$, leading to a well-defined $\mathrm{C} / \mathrm{O}$ range in which $\mathrm{N}: \mathrm{N}_{2}>1$. In this parameter space, the enhanced destruction of $\mathrm{CH}$ by $\mathrm{S}^{+}$ dominates the increase of atomic carbon in the gas phase, and the increase of $\mathrm{H}_{3} \mathrm{O}^{+}$does not compensate for the destruction of $\mathrm{OH}$ by $\mathrm{S}^{+}$.

Regarding nitrogen hydrides, a variation from low-tointermediate sulphur abundance does not change the abundances dramatically. This is not true when going from intermediate to high $[\mathrm{S}]_{\text {tot }}$. At high $\mathrm{C} / \mathrm{O},[\mathrm{NH}]$ drops by a factor of 5 , while $\mathrm{NH}_{2}$ is unaffected and remains at a very low abundance. The most dramatic change is that of $\left[\mathrm{NH}_{3}\right]$, which drops by a factor of 20. This is due to the combination of the two reactions $\mathrm{NH}_{3}+\mathrm{S}^{+} \longrightarrow \mathrm{NH}_{3}^{+}+\mathrm{S}$ and $\mathrm{NH}_{3}^{+}+\mathrm{e}^{-} \longrightarrow \mathrm{NH}+\mathrm{H}+\mathrm{H}$, which get greatly enhanced at high $[\mathrm{S}]_{\text {tot }}$. Their net effect is to transfer nitrogen from ammonia to NH. Nevertherless, the latter sees its amount divided by a factor 5 because the destruction path $\mathrm{NH}+\mathrm{N}$ becomes important in the $\mathrm{N}: \mathrm{N}_{2}>1$ regime.

\subsection{Comparison with observations}

Before the launch of the Herschel space telescope, the only astronomical source where the three hydrides $\mathrm{NH}, \mathrm{NH}_{2}$, and $\mathrm{NH}_{3}$ were detected was Sgr B2, with the ratios $\mathrm{NH}: \mathrm{NH}_{2}: \mathrm{NH}_{3} \sim$ 1:10:100 (Goicoechea et al. 2004). However, this line of sight encompasses a variety of physical conditions (e.g. shocks), and the $\mathrm{NH}: \mathrm{NH}_{2}: \mathrm{NH}_{3}$ ratios measured in Sgr B2 may therefore not be representative of cold dense clouds. Recent Herschel/HIFI observations towards the solar-type protostar IRAS 16293-2422, however, allowed putting strong constraints on the nitrogen hydride chemistry in dark gas (Hily-Blant et al. 2010a; Bacmann et al. 2010).

IRAS 16293-2422 is situated deep within a high column density core in a filament of the $\rho$ Oph cloud complex. From the results of extensive interferometric and single dish-mapping at centimetre, millimetre, and far-infrared wavelengths, detailed models of the physical structure of the source have been constructed (e.g. Crimier et al. 2010, and references therein). The region can be divided into four components: the ambient molecular cloud, the circumbinary envelope, the three protostellar sources A1, A2, and B, and the outflow components (see Loinard et al. 2013, and references therein). The total column density of 
$\mathrm{H}_{2}$ towards IRAS $16293-2422$ is $\sim 2 \times 10^{23} \mathrm{~cm}^{-2}$ (van Dishoeck et al. 1995). In the most external part of the source where nitrogen hydrides are seen in absorption, the column density is necessarily much lower. Radiative transfer computations where we have coupled non-local thermodynamic equilibrium (nonLTE) calculations with a simple physical model of the source (see Appendix A) have shown that the absorbing region must have an $\mathrm{H}_{2}$ density $\lesssim 10^{4} \mathrm{~cm}^{-3}$ (i.e. $n_{\mathrm{H}} \lesssim 2 \times 10^{4} \mathrm{~cm}^{-3}$ ), which corresponds not to the circumbinary envelope but to the ambient cloud (although the distinction is artificial since the density profile is continuous). For this component, the $\mathrm{H}_{2}$ column density is rather uncertain but we adopted the value derived from $\mathrm{C}^{18} \mathrm{O}$ observations by van Dishoeck et al. (1995), $N\left(\mathrm{H}_{2}\right)=$ $1.5 \times 10^{22} \mathrm{~cm}^{-2}$. We note that Hily-Blant et al. (2010a) employed a different value, $N\left(\mathrm{H}_{2}\right)=(5.5 \pm 2.5) \times 10^{22} \mathrm{~cm}^{-2}$, based on an extrapolation of the Crimier et al. profile. The $\mathrm{NH}_{3}$ column density derived by Hily-Blant et al. (2010a) was highly uncertain because, in contrast to $\mathrm{NH}$ and $\mathrm{NH}_{2}$, the hyperfine structure was not resolved. Guessed excitation temperatures of 8-10 K were therefore employed within an LTE treatment. In the present work, non-LTE radiative transfer calculations for $\mathrm{NH}$ and $\mathrm{NH}_{3}$ were performed, as described in Appendix A. The best agreement with the observations (see Fig. A.1) is obtained for a total ammonia column density of $1.4 \times 10^{15} \mathrm{~cm}^{-2}$. The associated gas temperature is $11 \mathrm{~K}$, which is fully consistent with standard dark cloud conditions. The spectrum of $\mathrm{NH}$ is also reproduced well (see Fig. A.2). The column density of $\mathrm{NH}_{2}$ has also been revised, since it had been estimated by Hily-Blant et al. (2010a) based on the $\mathrm{NH}_{2}$ (o) alone and assuming that the $\mathrm{NH}_{2}$ (p) abundance was negligible. However, our models, as well as Faure et al. (2013), show that this should not be the case and that the $\mathrm{o} / \mathrm{p}$ ratio of $\mathrm{NH}_{2}$ is more likely $\sim 2.3$. We have therefore increased the total column density of $\mathrm{NH}_{2}$ from $5.0 \times 10^{13}$ to $7.5 \times 10^{13} \mathrm{~cm}^{-2}$. Finally, the column densities of $\mathrm{NH}, \mathrm{NH}_{2}$, and $\mathrm{NH}_{3}$ used in this work are $(2.2 \pm 0.8) \times 10^{14}$, $(7.5 \pm 3.0) \times 10^{13}$, and $(1.4 \pm 1.0) \times 10^{15} \mathrm{~cm}^{-2}$, respectively, or abundance ratios $\mathrm{NH}: \mathrm{NH}_{2}: \mathrm{NH}_{3} \sim 3: 1: 19$. The corresponding abundances relative to the total $\mathrm{H}$ nuclei are then obtained using $N_{\mathrm{H}}=2 \times N\left(\mathrm{H}_{2}\right)=(3.0 \pm 1.5) \times 10^{22} \mathrm{~cm}^{-2}$.

The abundances of $\mathrm{NH}, \mathrm{NH}_{2}$, and $\mathrm{NH}_{3}$ towards IRAS 162932422 are compared in Fig. 4 to the set of models described previously. Overall, the predicted abundances match the observations only within a narrow range of $\mathrm{C} / \mathrm{O}$ ratios, which is found to be $0.7-0.8$. However, as discussed above, the uncertainties on the abundances are rather large due to the difficulty to estimate the $\mathrm{H}_{2}$ column density in the absorbing layers. In contrast, abundance (or column density) ratios circumvent this caveat, and are thus more robust. The ratios $\mathrm{NH}_{2}: \mathrm{NH}$ and $\mathrm{NH}_{3}: \mathrm{NH}$ are plotted in Fig. 5. At low and intermediate sulphur abundance, the $\mathrm{NH}_{2}: \mathrm{NH}$ ratio delineates a narrow range of $\mathrm{C} / \mathrm{O}$ values of $0.75-0.80$ consistent with the above constraints. At intermediate sulphur abundance, the $\mathrm{NH}_{3}: \mathrm{NH}$ ratio further constrains the $\mathrm{C} / \mathrm{O}$ ratio to 0.75 . For a high sulphur abundance, however, there is no $\mathrm{C} / \mathrm{O}$ that allows both abundance ratios to be reproduced simultaneously. From Fig. 2, which shows the evolution with time of the abundances, we note that the observed abundance ratios $\mathrm{NH}: \mathrm{NH}_{2}: \mathrm{NH}_{3}$ are also well reproduced at very early times $\approx 4 \times 10^{4}$ yr. However, at such early times, the fractional abundances of the N-hydrides are more than an order of magnitude smaller than observed. Although there was no minimisation attempt, the best agreement with the observations is found for the set of parameters $[\mathrm{S}]_{\mathrm{tot}}=8.0 \times 10^{-8}$ and $\mathrm{C} / \mathrm{O}=0.8$, which will be referred to as our best model.
We conclude that the steady-state abundances predicted by our gas-phase chemical model are consistent with the observational constraints on the abundances and abundance ratios of $\mathrm{NH}, \mathrm{NH}_{2}$, and $\mathrm{NH}_{3}$, provided that the $\mathrm{C} / \mathrm{O}$ ratio is $\sim 0.8$. The elemental abundance of sulphur is less constrained, but must be depleted by more than a factor of 2 .

\subsection{Impact of the new rates}

To show the influence of the new rates adopted in our network, we performed a calculation using the Flower network combined with our best model parameters. The abundances of $\mathrm{NH}_{2}$ and $\mathrm{NH}_{3}$ are similar to those found with our updated network, with differences less than $30 \%$. However, this is not true for $\mathrm{NH}$ abundance, which is one order of magnitude lower with the old network. This large increase in our model is due to the dissociative recombination channel of $\mathrm{N}_{2} \mathrm{H}^{+}$forming $\mathrm{NH}$, as already noted in Dislaire et al. (2012). When looking into more detail, the relatively small change of the abundances of $\mathrm{NH}_{2}$ and $\mathrm{NH}_{3}$ in fact results from a combination of three effects. First, the updated rate of the reaction $\mathrm{N}^{+}+\mathrm{H}_{2}$ lowers the abundances of $\mathrm{NH}_{2}$ and $\mathrm{NH}_{3}$ by more than a factor of 10 . For ammonia, this effect is partially compensated for by the updated branching ratios of the $\mathrm{NH}_{\mathrm{n}}^{+}+\mathrm{e}^{-}$dissociative recombinations. The abundance of $\mathrm{NH}_{2}$ and that of ammonia are finally recovered when updating the rate and branching ratios of the reaction $\mathrm{H}_{3}^{+}+\mathrm{O}$. This reaction produces more $\mathrm{OH}^{+}$and $\mathrm{H}_{2} \mathrm{O}^{+}$, thus enhancing the amount of $\mathrm{OH}$, hence the $\mathrm{N}$ to $\mathrm{N}_{2}$ conversion. This demonstrates that updating all those reaction rates is essential for reproducing the abundances of nitrogen hydrides. We note that the Dislaire et al. (2012) model, based on the osu.09.2008 chemical network ${ }^{2}$, predicts abundances that are too small for all three species, which may result from the large sulphur abundance assumed by these authors, although the comparison is not direct because the two chemical networks may contain different rate coefficients for non-negligible reactions.

The impact of the new rates is further proven by the $\mathrm{o} / \mathrm{p}$ of $\mathrm{NH}_{2}$ and $\mathrm{NH}_{3}$ predicted by our models, which are 2.3 and 0.7 , respectively (see Table 3 ). These values are significantly higher than those obtained with the Flower et al. (2006a) network ( 1 and 0.3 , respectively, see Table 3 ). It should be noted that both $o / p$ ratios are below the statistical values of 3 and 1, respectively, which are lower limits under thermal equilibrium. In addition, these $\mathrm{o} / \mathrm{p}$ ratios were found to depend only very weakly on the $\mathrm{C} / \mathrm{O}$ value, as expected since the $\mathrm{o} / \mathrm{p}$ of nitrogen hydrides are driven by the $\mathrm{o} / \mathrm{p}$ ratio of $\mathrm{H}_{2}$ (see Sect. 2.4 and Fig. 4).

\section{Discussion and conclusions}

We have presented a new gas-phase, ortho/para, chemical network devoted to the interstellar chemistry of nitrogen under typical dark cloud physical conditions. More specifically, this work focussed on nitrogen hydrides because these species, which are linked by a small number of chemical reactions, have been observed with high accuracy with the Herschel/HIFI instrument. The absorption lines of $\mathrm{NH}, \mathrm{NH}_{2}$, and $\mathrm{NH}_{3}$ trace the cold, UVshielded, and moderately dense envelope of the IRAS 162932422 protostar, and therefore provide direct observational tests of the chemistry of nitrogen in such environments. Although the comparison deals with a single object, the present work aims at understanding general processes of nitrogen chemistry in dark cloud conditions.

\footnotetext{
2 http://www . physics. ohio-state. edu/ eric/research. html
} 

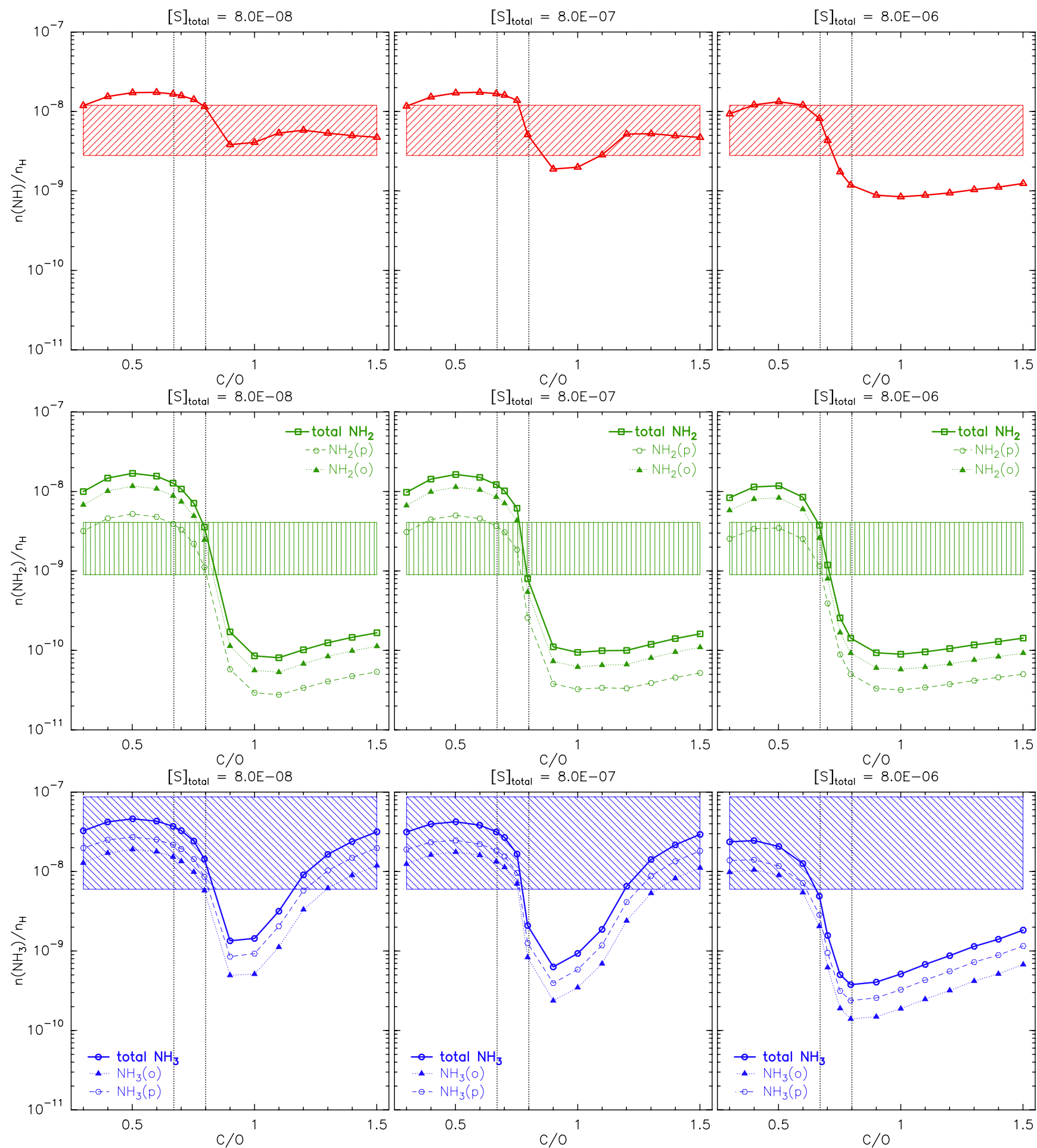

Fig. 4. Steady-state abundances of $\mathrm{NH}, \mathrm{NH}_{2}$, and $\mathrm{NH}_{3}$ as a function of the $\mathrm{C} / \mathrm{O}$ gas-phase elemental abundance ratio for three different values of gas-phase elemental abundance of sulphur (from left to right: $[\mathrm{S}]_{\mathrm{tot}}=8.0 \times 10^{-8}, 8.0 \times 10^{-7}, 8.0 \times 10^{-6}$ ). $\mathrm{C} / \mathrm{O}$ values include $0.3,0.4,0.5,0.6$, $0.67,0.7,0.75,0.8,0.9,1.0,1.1,1.2,1.3,1.4,1.5$. In each panel, the solid line refers to the model predictions and the vertical dashed lines locate $\mathrm{C} / \mathrm{O}=0.67$ (Flower et al. 2006 value) and 0.8 (our best model value). For $\mathrm{NH}_{2}$ and $\mathrm{NH}_{3}$, the ortho and para abundances are shown separately (dashed and dotted lines respectively). The observed abundances towards IRAS 16293-2422 are represented by the hatched boxes, considering an $\mathrm{o} / \mathrm{p}$ ratio of $\mathrm{NH}_{2} \sim 2$, as predicted by our model.

Our network is based on the gas-phase network of Flower et al. (2006a) where the following major improvements have been implemented: i) the nitrogen chemistry was revised using the most recent experimental results, in particular for the conversion of $\mathrm{N}$ to $\mathrm{N}_{2}$ through radical-radical reactions and for the dissociative recombinations of the $\mathrm{NH}_{\mathrm{n}}^{+}(n=2-4)$ ions; ii) we adopted recent theoretical results for the ortho-to-para conversion of $\mathrm{H}_{2}$ by $\mathrm{H}^{+}$and $\mathrm{H}_{3}^{+}$; iii) we employed the formalism of Oka (2004), as detailed in Rist et al. (2013) and Faure et al. (2013), to derive the nuclear spin branching ratios for all primary reactions involved in the formation and destruction of $\mathrm{H}_{2}(\mathrm{p}), \mathrm{H}_{2}(\mathrm{o}), \mathrm{NH}$, $\mathrm{NH}_{2}(\mathrm{p}), \mathrm{NH}_{2}(\mathrm{o}), \mathrm{NH}_{3}(\mathrm{p})$, and $\mathrm{NH}_{3}(\mathrm{o})$. 

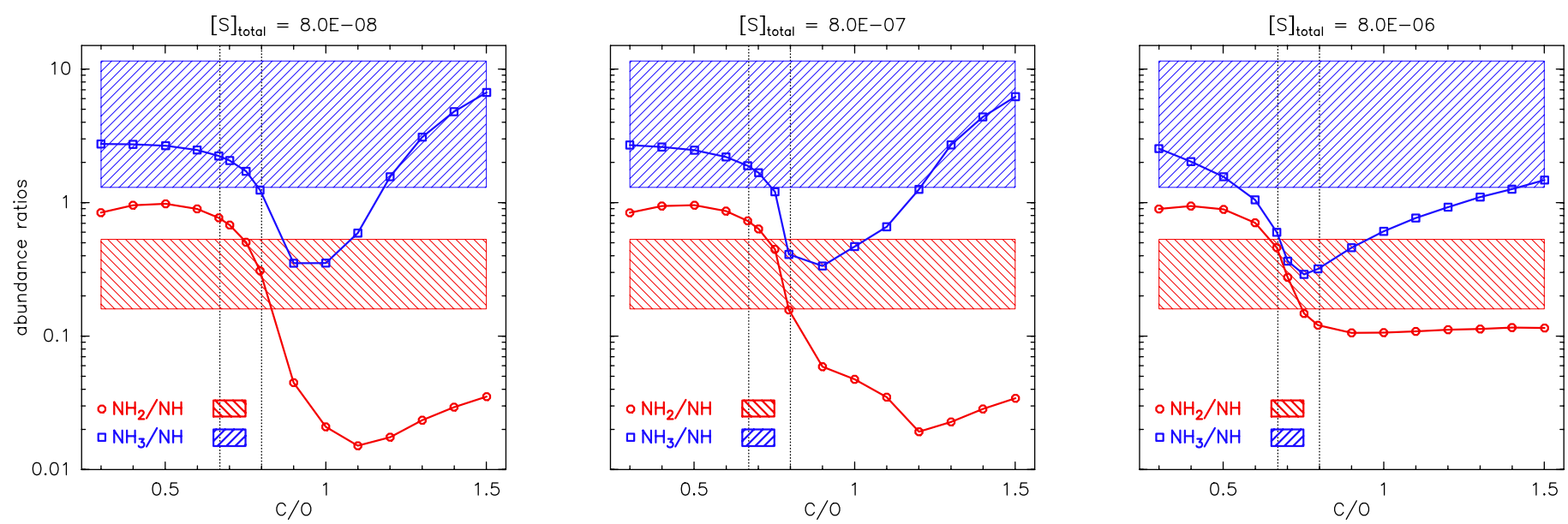

Fig. 5. Steady-state abundance ratios of the $\mathrm{N}$-hydrides as a function of the gas-phase elemental abundance ratio of $\mathrm{C} / \mathrm{O}$ for three different values of the gas-phase elemental abundance of sulphur (from left to right: $[\mathrm{S}]_{\text {tot }}=8.0 \times 10^{-8}, 8.0 \times 10^{-7}, 8.0 \times 10^{-6}$ ). C/O values include $0.3,0.4,0.5$, $0.6,0.67,0.7,0.75,0.8,0.9,1.0,1.1,1.2,1.3,1.4,1.5$. In all panels, the vertical dashed lines locate $\mathrm{C} / \mathrm{O}=0.67$ (Flower et al. 2006 value) and 0.8 (our best model value). The abundances derived from Herschel/HIFI observations towards IRAS 16293-2422 are represented by the hatched boxes, considering an $\mathrm{o} / \mathrm{p}$ ratio of $\mathrm{NH}_{2} \sim 2$, as predicted by our model.

Table 3. Abundances and abundance ratios of nitrogen hydrides at steady state predicted using several chemical networks.

\begin{tabular}{|c|c|c|c|c|c|}
\hline & \multicolumn{2}{|c|}{ Observations $^{a}$} & \multicolumn{2}{|l|}{ Models } & \multirow[b]{2}{*}{ Flower et al. $(2006 \mathrm{a})^{d}$} \\
\hline & $N\left(\mathrm{~cm}^{-2}\right)$ & $N / N_{\mathrm{H}}$ & Dislaire et al. $(2012)^{b}$ & This work $^{c}$ & \\
\hline NH & $2.2 \pm 0.8(14)$ & $7.3 \pm 4.5(-9)$ & $4.3(-10)$ & $1.2(-8)$ & $1.3(-9)$ \\
\hline $\mathrm{NH}_{2}(\mathrm{o})$ & $5.0 \pm 0.9(13)$ & $1.7 \pm 0.9(-9)$ & - & $2.5(-9)$ & $2.0(-9)$ \\
\hline $\mathrm{NH}_{2}(\mathrm{p})$ & - & - & - & $1.1(-9)$ & $2.0(-9)$ \\
\hline $\mathrm{NH}_{2}$ & $7.5 \pm 3.0(13)$ & $2.5 \pm 1.6(-9)$ & $8.2(-11)$ & $3.6(-9)$ & $4.0(-9)$ \\
\hline $\mathrm{NH}_{3}(\mathrm{o})$ & - & - & - & $5.8(-9)$ & $2.5(-9)$ \\
\hline $\mathrm{NH}_{3}(\mathrm{p})$ & - & - & - & $8.6(-9)$ & $7.3(-9)$ \\
\hline $\mathrm{NH}_{3}$ & $1.4 \pm 1.0(15)$ & $4.7 \pm 4.1(-8)$ & $7.5(-10)$ & $1.4(-8)$ & $9.8(-9)$ \\
\hline $\mathrm{NH}_{2}: \mathrm{NH}$ & & $0.34 \pm 0.18$ & 0.2 & 0.3 & 3.1 \\
\hline $\mathrm{NH}_{3}: \mathrm{NH}$ & & $6.4 \pm 5.2$ & 1.7 & 1.2 & 7.5 \\
\hline $\mathrm{NH}: \mathrm{NH}_{2}: \mathrm{NH}_{3}$ & & $3: 1: 19$ & $5: 1: 9$ & $3: 1: 3$ & $0.3: 1: 2.5$ \\
\hline
\end{tabular}

Notes. Constant physical conditions were adopted: $T_{\text {kin }}=10 \mathrm{~K}, n_{\mathrm{H}}=10^{4} \mathrm{~cm}^{-3}, \zeta=1.3 \times 10^{-17} \mathrm{~s}^{-1}$. Numbers in parentheses are powers of ten. (a) Based on Hily-Blant et al. (2010a) and revised as described in Appendix A. For each species, $N$ is the total column density. The adopted value of $N_{\mathrm{H}}=3.0 \pm 1.5 \times 10^{22} \mathrm{~cm}^{-2}$. ${ }^{(b)}$ Updated version of the osu.09.2008 network used in Dislaire et al. (2012), who adopted $\mathrm{C} / \mathrm{O}=0.67$ and $[\mathrm{S}]_{\mathrm{tot}}=1.5 \times 10^{-5} .{ }^{(c)}$ Our network with the parameters of our best model: $\mathrm{C} / \mathrm{O}=0.8\left(\right.$ or $\left.[\mathrm{O}]_{\mathrm{tot}}=1.04 \times 10^{-4}\right)$ and $[\mathrm{S}]_{\mathrm{tot}}=8 \times 10^{-8}$. ${ }^{(d)}$ Network from Flower et al. (2006a) adopting the parameters of our best model.

Our findings may be summarised as follows. First, we found that the abundances of the nitrogen hydrides strongly depend on the gas-phase elemental $\mathrm{C} / \mathrm{O}$ ratio adopted in the model. A similar result was noted in earlier works (e.g. Terzieva \& Herbst 1998; Hily-Blant et al. 2010b; Tassis et al. 2012), although we here provided a detailed analysis of the influence of the $\mathrm{C} / \mathrm{O}$ ratio, by focussing on a smaller set of species. The influence of the $\mathrm{C} / \mathrm{O}$ ratio stems from the fact that nitrogen hydrides derive from $\mathrm{N}_{2}$ that is formed via either $\mathrm{N}+\mathrm{CH}$ or $\mathrm{N}+\mathrm{OH}$. Two regimes corresponding to $\mathrm{C} / \mathrm{O}<0.8$ and $\mathrm{C} / \mathrm{O}>1$ are clearly identified where the $\mathrm{N}_{2} / \mathrm{N}$ ratio is greater than 1 and the abundance of ammonia is a few $10^{-8}$. In contrast, the abundances of $\mathrm{NH}$ and $\mathrm{NH}_{2}$ are much lower at high $\mathrm{C} / \mathrm{O}$ because these radicals are efficiently destroyed by atomic carbon. Second, we have shown that increasing the elemental gas-phase abundance of sulphur $[\mathrm{S}]_{\text {tot }}$ significantly reduces the efficiency of the $\mathrm{N}$ to $\mathrm{N}_{2}$ conversion. Thus a high abundance of sulphur (i.e. $8.0 \times 10^{-6}$ ) was found to reduce the abundance of several $\mathrm{N}$-bearing species by up to two orders of magnitude.
The steady-state abundances predicted by our model were compared to the Herschel/HIFI observations of $\mathrm{NH}, \mathrm{NH}_{2}$, and $\mathrm{NH}_{3}$, towards the low-mass protostar IRAS 16293-2422. Our chemical model reproduces both the observed abundances and abundance ratios of the three hydrides well. A key point is that our network produces more $\mathrm{NH}$ than $\mathrm{NH}_{2}$, as observed. Our best model, which leads to $\mathrm{NH}: \mathrm{NH}_{2}: \mathrm{NH}_{3}$ abundance ratios of 3:1:3 (see Table 3), is obtained for a $\mathrm{C} / \mathrm{O}$ ratio of 0.8 and a low sulphur abundance $[\mathrm{S}]_{\text {tot }}=8.0 \times 10^{-8}$. Although it is consistent with the 3:1:19 observed ratios, the predicted abundance of ammonia is at the lower end of the allowed range. Higher values for $[\mathrm{S}]_{\text {tot }}$ are also possible, but a high abundance of $8.0 \times 10^{-6}$ is clearly excluded by our models, as well as $\mathrm{C} / \mathrm{O}$ ratios outside the range $0.7-0.8$. We note that at earlier times $(\sim 2-5 \mathrm{Myr})$, the observations can be reproduced with a similar $[\mathrm{S}]_{\text {tot }}$ (i.e. $<8.0 \times 10^{-6}$ ) and slightly higher $\mathrm{C} / \mathrm{O}$ ratios, in the range 0.9 to 1.1 .

Our model calculations thus show that chemical reactive processes on dust grains are not needed to explain the gas-phase 
abundances of nitrogen hydrides in typical dark cloud conditions. This of course does not preclude the possibility that a fraction of atomic nitrogen can also form ammonia ices by hydrogenation on the grain mantles. This process is in fact certainly necessary to account for the high abundance of ammonia $\left(\sim 10^{-6}\right)$ detected in e.g. shock regions, where grain mantles are released in the gas phase (Umemoto et al. 1999). We note that our best model corresponds to a regime where $\mathrm{N} / \mathrm{N}_{2} \approx 1$. The exact amount of gaseous $\mathrm{N}_{2}$, however, depends on the competition between its formation in the gas and the depletion of atomic nitrogen onto grains, which was neglected in the present work. Several nitrogenated species were shown observationally to resist depletion in cold prestellar cores, in contrast to $\mathrm{CO}$ and many other species. This is the case for $\mathrm{NH}_{3}, \mathrm{~N}_{2} \mathrm{H}^{+}$, and CN (Tafalla et al. 2004; Crapsi et al. 2007; Hily-Blant et al. 2008), and also for $\mathrm{HCN}$ (and HNC), although for the last there seems to exist some variability amongst sources (Hily-Blant et al. 2010b; Padovani et al. 2011; Pagani et al. 2012). This observational result indicates that enough atomic $\mathrm{N}$ is always available in the gas phase, which is also slowly converted into $\mathrm{N}_{2}$. However, in similar objects, Akyilmaz et al. (2007) observes that NO disappears from the gas phase at high densities where $\mathrm{CN}$ does not, which was interpreted as freeze-out onto grains. The different behaviours among $\mathrm{N}$-bearing species with respect to depletion could result from a combination of several factors, such as different molecular properties (e.g. the binding energy) and/or the timescales of the gas-phase chemical reactions. Further attempts to reproduce, in a comprehensive fashion, the behaviours of the observed species, may need to consider all these aspects taking the time-dependent competition between gas-phase and gasgrain processes into account.

Gas-phase synthesis of N-hydrides is further supported by the ortho-to-para ratios of $\mathrm{NH}_{3}$ and $\mathrm{NH}_{2}$ predicted by our model. Persson et al. (2012) measured the ortho- and para-ammonia column densities in diffuse molecular clouds along the sight lines towards the high-mass star-forming regions W49N and G10.60.4 , and found $\mathrm{o} / \mathrm{p}\left(\mathrm{NH}_{3}\right) \approx 0.5-0.7$. This ratio is in excellent agreement with our prediction. For $\mathrm{NH}_{2}$, preliminary Herschel measurements indicate ortho-to-para values in the range 1.5-3.5 in diffuse gas along the line of sight towards G10.6-0.4 (C.M. Persson et al., priv. comm.), again in very good agreement with our prediction. The $\mathrm{NH}, \mathrm{NH}_{2}$, and $\mathrm{NH}_{3}$ abundances (relative to total hydrogen) derived by Persson et al. (2010) are $5.6 \times 10^{-9}$, $3.0 \times 10^{-9}$, and $3.2 \times 10^{-9}$, respectively, or abundance ratios $\mathrm{NH}: \mathrm{NH}_{2}: \mathrm{NH}_{3}=2: 1: 1$. The $\mathrm{NH}$ and $\mathrm{NH}_{2}$ abundances are thus similar to those in the envelope surrounding IRAS 16293-2422 (see Table 3), although that of ammonia is one order of magnitude lower. Their abundance ratios are in fact similar to the prediction of our best model (see Table 3). However, our calculations are not likely to apply to a warmer and more tenuous diffuse gas, which requires dedicated models (gas density of $\sim 10^{3} \mathrm{~cm}^{-3}$ and temperature of $\sim 30 \mathrm{~K}$ ). In particular, the $\mathrm{C} / \mathrm{O}$ ratio and $[\mathrm{S}]_{\text {tot }}$ abundance may take different values in the diffuse ISM. Photodissociation of ammonia may also play a role, as discussed by Persson et al. (2010), although we do not expect the $\mathrm{UV}$ to significantly alter the $\mathrm{o} / \mathrm{p}$ of $\mathrm{NH}_{2}$ and $\mathrm{NH}_{3}$ which are driven by proton exchange reactions.

The present work gives rise to several questions. First, additional observations of $\mathrm{NH}, \mathrm{NH}_{2}$, and $\mathrm{NH}_{3}$ in various objects are needed to confirm the gas-phase chemical processes mentioned above. The determination of the ortho-to-para ratio towards others Class 0 protostars would also be extremely useful. Another critical issue is related to the abundances of other $\mathrm{N}$-bearing species such as $\mathrm{N}_{2} \mathrm{H}^{+}, \mathrm{CN}$, and nitriles (e.g. $\mathrm{HCN}$ ) in dark clouds. Observations in dark clouds are already available for these species, but were not discussed in this paper. The reason is that we believe that such a comprehensive comparison with all the observations first requires assessing the completeness of the current chemical network with respect to all those simple nitrogen-bearing species.

Here, we have focussed on nitrogen hydrides, and this allowed us to understand several effects and explain various observational facts. Of course, chemistry is highly non-linear (e.g. Le Bourlot et al. 1995), and we cannot exclude that in some peculiar range of parameters, new rates, e.g. in the formation of $\mathrm{HCN}$, could affect the above results. However, by exploring such a broad range of initial abundances, we have been able to emphasise robust trends and processes. Our approach is complementary to other strategies that quantify the sensitivity of chemical networks to rate uncertainties (e.g. Wakelam et al. 2010). Time-dependent aspects must also be explored, taking gas-grain processes into account and/or including the effect of gas dynamics (e.g. Brown \& Charnley 1990; Flower et al. 2006a; Tassis et al. 2012).

Concerning future improvements of our network, we are currently implementing new reaction rates and nuclear spin branching ratios for the deuterated isotopologues of several nitrogenbearing species. Both deuterated and ${ }^{15} \mathrm{~N}$ isotopologues were not considered in the present work. However, both are detected in the cold ISM with significant abundances. The molecular D/H and ${ }^{15} \mathrm{~N} /{ }^{14} \mathrm{~N}$ ratios are sensitive probes of the chemistry, and future works will explore gas-phase fractionation processes and the possible link with the $\mathrm{D}$ and ${ }^{15} \mathrm{~N}$-enrichments observed in solar system objects (see e.g. Wirström et al. 2012; Hily-Blant et al. 2013a, and references therein). We note in this context the recent detection of $\mathrm{C}^{15} \mathrm{~N}$ and $\mathrm{NH}_{3} \mathrm{D}^{+}$in cold prestellar cores by Hily-Blant et al. (2013b) and Cernicharo et al. (2013), respectively.

Acknowledgements. We thank our anonymous referee for a careful reading and useful comments that improved the manuscript. This work has been supported by "Région Rhône-Alpes" (CIBLE programme), the Agence Nationale de la Recherche (ANR-HYDRIDES), contract ANR-12-BS05-0011-01, and by the CNRS national programme "Physico-Chimie du Milieu Interstellaire".

\section{References}

Akyilmaz, M., Flower, D. R., Hily-Blant, P., Pineau des Forêts, G., \& Walmsley, C. M. 2007, A\&A, 462, 221

Anicich, V. G., \& Huntress, Jr., W. T. 1986, ApJS, 62, 553

Asplund, M., Grevesse, N., Sauval, A. J., \& Scott, P. 2009, ARA\&A, 47, 481

Bacmann, A., Caux, E., Hily-Blant, P., et al. 2010, A\&A, 521, L42

Bergeat, A. 1999, Chem. Phys. Lett., 308, 7

Bergeat, A., Hickson, K. M., Daugey, N., Caubet, P., \& Costes, M. 2009, Phys. Chem. Chem. Phys., 11, 8149

Bergin, E. A., \& Langer, W. D. 1997, ApJ, 486, 316

Bergin, E. A., \& Tafalla, M. 2007, ARA\&A, 45, 339

Boogert, A. C. A., Huard, T. L., Cook, A. M., et al. 2011, ApJ, 729, 92

Bottinelli, S., Boogert, A. C. A., Bouwman, J., et al. 2010, ApJ, 718, 1100

Brinch, C., \& Hogerheijde, M. R. 2010, A\&A, 523, A25

Brown, P. D., \& Charnley, S. B. 1990, MNRAS, 244, 432

Cartledge, S. I. B., Lauroesch, J. T., Meyer, D. M., \& Sofia, U. J. 2004, ApJ, 613, 1037

Caselli, P., Walmsley, C. M., Terzieva, R., \& Herbst, E. 1998, ApJ, 499, 234

Ceccarelli, C., Bacmann, A., Boogert, A., et al. 2010, A\&A, 521, L22

Cernicharo, J., Tercero, B., Fuente, A., et al. 2013, ApJ, 771, L10

Charnley, S. B., \& Rodgers, S. D. 2002, ApJ, 569, L133

Chastaing, D., Le Picard, S. D., \& Sims, I. R. 2000, J. Chem. Phys., 112, 8466

Cheung, A. C., Rank, D. M., Townes, C. H., Thornton, D. D., \& Welch, W. J. 1968, Phys. Rev. Lett., 21, 1701

Crabtree, K. N., Indriolo, N., Kreckel, H., Tom, B. A., \& McCall, B. J. 2011, ApJ, 729, 15

Crapsi, A., Caselli, P., Walmsley, M. C., \& Tafalla, M. 2007, A\&A, 470, 221

Crimier, N., Ceccarelli, C., Maret, S., et al. 2010, A\&A, 519, A65 
Crutcher, R. M. 2012, ARA\&A, 50, 29

Dalgarno, A., Black, J. H., \& Weisheit, J. C. 1973, Astrophys. Lett., 14, 77

Daranlot, J., Jorfi, M., Xie, C., et al. 2011, Science, 334, 1538

Daranlot, J., Hincelin, U., Bergeat, A., et al. 2012, Proc. National Academy of Science, 109, 10233

D’Hendecourt, L. B., Allamandola, L. J., \& Greenberg, J. M. 1985, A\&A, 152, 130

Dislaire, V., Hily-Blant, P., Faure, A., et al. 2012, A\&A, 537, A20

Dos Santos, S. F., Kokoouline, V., \& Greene, C. H. 2007, J. Chem. Phys., 127, 124309

Dumouchel, F., Kłos, J., Toboła, R., et al. 2012, J. Chem. Phys., 137, 114306

Faure, A., Hily-Blant, P., Le Gal, R., Rist, C., \& Pineau des Forêts, G. 2013, ApJ, 770, L2

Flower, D. R., Pineau des Forêts, G., \& Walmsley, C. M. 2005, A\&A, 436, 933

Flower, D. R., Pineau des Forêts, G., \& Walmsley, C. M. 2006a, A\&A, 456, 215

Flower, D. R., Pineau des Forêts, G., \& Walmsley, C. M. 2006b, A\&A, 449, 621

Gerin, M., Viala, Y., Pauzat, F., \& Ellinger, Y. 1992, A\&A, 266, 463

Gerlich, D. 1993, J. Chem. Soc. Faraday Trans., 89, 2199

Gibb, E. L., Whittet, D. C. B., Schutte, W. A., et al. 2000, ApJ, 536, 347

Goicoechea, J. R., Rodríguez-Fernández, N. J., \& Cernicharo, J. 2004, ApJ, 600, 214

Graedel, T. E., Langer, W. D., \& Frerking, M. A. 1982, ApJS, 48, 321

Grussie, F., Berg, M. H., Crabtree, K. N., et al. 2012, ApJ, 759, 21

Hasegawa, T. I., \& Herbst, E. 1993, MNRAS, 261, 83

Herbst, E., \& Klemperer, W. 1973, ApJ, 185, 505

Herbst, E., Defrees, D. J., \& McLean, A. D. 1987, ApJ, 321, 898

Herbst, E., Terzieva, R., \& Talbi, D. 2000, MNRAS, 311, 869

Hidaka, H., Watanabe, M., Kouchi, A., \& Watanabe, N. 2011, Phys. Chem. Chem. Phys., 13, 15798

Hily-Blant, P., Walmsley, M., Pineau des Forêts, G., \& Flower, D. 2008, A\&A, 480, L5

Hily-Blant, P., Maret, S., Bacmann, A., et al. 2010a, A\&A, 521, L52

Hily-Blant, P., Walmsley, M., Pineau des Forêts, G., \& Flower, D. 2010b, A\&A, 513, A41

Hily-Blant, P., Bonal, L., Faure, A., \& Quirico, E. 2013a, Icarus, 223, 582

Hily-Blant, P., Pineau des Forêts, G., Faure, A., Le Gal, R., \& Padovani, M. 2013b, A\&A, 557, A65

Hirota, T., Yamamoto, S., Mikami, H., \& Ohishi, M. 1998, ApJ, 503, 717

Ho, P. T. P., \& Townes, C. H. 1983, ARA\&A, 21, 239

Hogerheijde, M. R., \& van der Tak, F. F. S. 2000, A\&A, 362, 697

Hollenbach, D., \& Salpeter, E. E. 1971, ApJ, 163, 155

Honvault, P., Jorfi, M., González-Lezana, T., Faure, A., \& Pagani, L. 2011, Phys. Chem. Chem. Phys., 13, 19089

Honvault, P., Jorfi, M., González-Lezana, T., Faure, A., \& Pagani, L. 2012, Phys. Rev. Lett., 108, 109903

Hugo, E., Asvany, O., \& Schlemmer, S. 2009, J. Chem. Phys., 130, 164302 Jenkins, E. B. 2009, ApJ, 700, 1299

Jensen, M. J., Bilodeau, R. C., Safvan, C. P., et al. 2000, ApJ, 543, 764

Jorfi, M., \& Honvault, P. 2009, J. Phys. Chem. A, 113, 10648

Jorfi, M., Honvault, P., \& Halvick, P. 2009, Chem. Phys. Lett., 471, 65

Knauth, D. C., Andersson, B.-G., McCandliss, S. R., \& Warren Moos, H. 2004, Nature, 429, 636

Le Bourlot, J. 1991, A\&A, 242, 235

Le Bourlot, J., Pineau des Forêts, G., Roueff, E., \& Flower, D. R. 1995, A\&A, 302, 870

Li, X., Heays, A. N., Visser, R., et al. 2013, A\&A, 555, A14

Loinard, L., Zapata, L. A., Rodríguez, L. F., et al. 2013, MNRAS, 430, L10

Maret, S., Bergin, E. A., \& Lada, C. J. 2006, Nature, 442, 425

Maret, S., Faure, A., Scifoni, E., \& Wiesenfeld, L. 2009, MNRAS, 399, 425
Marquette, J. B., Rebrion, C., \& Rowe, B. R. 1988, J. Chem. Phys., 89, 2041

Marquette, J. B., Rebrion, C., \& Rowe, B. R. 1989, A\&A, 213, L29

McCall, B. J., Huneycutt, A. J., Saykally, R. J., et al. 2004, Phys. Rev. A, 70, 052716

Mendes, M. B., Buhr, H., Berg, M. H., et al. 2012, ApJ, 746, L8

Mitchell, B. 1990, Phys. Rep., 186, 215

Nieva, M.-F., \& Przybilla, N. 2012, A\&A, 539, A143

Öjekull, J., Andersson, P. U., Någård, M. B., et al. 2004, J. Chem. Phys., 120, 7391

Oka, T. 2004, J. Mol. Spectr., 228, 635

Pachucki, K., \& Komasa, J. 2008, Phys. Rev. A, 77, 030501

Padovani, M., Walmsley, C. M., Tafalla, M., Hily-Blant, P., \& Pineau des Forêts, G. 2011, A\&A, 534, A77

Pagani, L., Bacmann, A., Cabrit, S., \& Vastel, C. 2007, A\&A, 467, 179

Pagani, L., Vastel, C., Hugo, E., et al. 2009, A\&A, 494, 623

Pagani, L., Bourgoin, A., \& Lique, F. 2012, A\&A, 548, L4

Persson, C. M., Black, J. H., Cernicharo, J., et al. 2010, A\&A, 521, L45

Persson, C. M., De Luca, M., Mookerjea, B., et al. 2012, A\&A, 543, A145

Pineau des Forêts, G., Roueff, E., \& Flower, D. R. 1990, MNRAS, 244, 668

Prasad, S. S., \& Huntress, Jr., W. T. 1980, ApJS, 43, 1

Przybilla, N., Nieva, M.-F., \& Butler, K. 2008, ApJ, 688, L103

Raich, J. C., \& Good, Jr., R. H. 1964, ApJ, 139, 1004

Rist, C., Faure, A., Hily-Blant, P., \& Le Gal, R. 2013, J. Phys. Chem. A, 117, 9800

Ruffle, D. P., Hartquist, T. W., Caselli, P., \& Williams, D. A. 1999, MNRAS, 306,691

Sandford, S. A., Bernstein, M. P., Allamandola, L. J., Goorvitch, D., \& Teixeira, T. C. V. S. 2001, ApJ, 548, 836

Sarrasin, E., Abdallah, D. B., Wernli, M., et al. 2010, MNRAS, 404, 518

Sipilä, O., Caselli, P., \& Harju, J. 2013, A\&A, 554, A92

Sofia, U. J., Parvathi, V. S., Babu, B. R. S., \& Murthy, J. 2011, AJ, 141, 22

Suzuki, H., Yamamoto, S., Ohishi, M., et al. 1992, ApJ, 392, 551

Tafalla, M., Myers, P. C., Caselli, P., \& Walmsley, C. M. 2004, A\&A, 416, 191

Tassis, K., \& Mouschovias, T. C. 2004, ApJ, 616, 283

Tassis, K., Willacy, K., Yorke, H. W., \& Turner, N. J. 2012, ApJ, 753, 29

Terzieva, R., \& Herbst, E. 1998, ApJ, 501, 207

Thaddeus, P. 1972, ARA\&A, 10, 305

Thomas, R. D., Hellberg, F., Neau, A., et al. 2005, Phys. Rev. A, 71, 032711

Tieftrunk, A., Pineau des Forêts, G., Schilke, P., \& Walmsley, C. M. 1994, A\&A, 289,579

Tielens, A. G. G. M., \& Hagen, W. 1982, A\&A, 114, 245

Troscompt, N., Faure, A., Maret, S., et al. 2009, A\&A, 506, 1243

Umemoto, T., Mikami, H., Yamamoto, S., \& Hirano, N. 1999, ApJ, 525, L105

van Dishoeck, E. F., \& Blake, G. A. 1998, ARA\&A, 36, 317

van Dishoeck, E. F., Blake, G. A., Jansen, D. J., \& Groesbeck, T. D. 1995, ApJ, 447, 760

Vigren, E., Zhaunerchyk, V., Hamberg, M., et al. 2012, ApJ, 757, 34

Wakelam, V., Selsis, F., Herbst, E., \& Caselli, P. 2005, A\&A, 444, 883

Wakelam, V., Smith, I. W. M., Herbst, E., et al. 2010, Space Sci. Rev., 156, 13

Wakelam, V., Herbst, E., Loison, J.-C., et al. 2012, ApJS, 199, 21

Walmsley, C. M., Flower, D. R., \& Pineau des Forêts, G. 2004, A\&A, 418, 1035

Whittet, D. C. B. 2010, ApJ, 710, 1009

Whittet, D. C. B., Bode, M. F., Baines, D. W. T., Longmore, A. J., \& Evans, A. 1983, Nature, 303, 218

Wirström, E. S., Charnley, S. B., Cordiner, M. A., \& Milam, S. N. 2012, ApJ, 757, L11

Womack, M., Ziurys, L. M., \& Wyckoff, S. 1992, ApJ, 393, 188

Zymak, I., Hejduk, M., Mulin, D., et al. 2013, ApJ, 768, 86 


\section{Appendix A: Radiative transfer modelling}

Our one-dimensional spherical source model consists in twolayers with uniform density and kinetic temperature. The inner layer, close to the protostar, has a radius of $10^{4} \mathrm{AU}$, a dust temperature of $30 \mathrm{~K}$, and a total (front + back) column density $N\left(\mathrm{H}_{2}\right)=6.6 \times 10^{22} \mathrm{~cm}^{-2}-$ hence, a density $n\left(\mathrm{H}_{2}\right)=$ $4.4 \times 10^{5} \mathrm{~cm}^{-3}-$ and we assume this layer does not contain gas-phase nitrogen hydrides. Furthermore, the dust opacity is assumed to vary as a power-law of the wavelength, with a spectral index $(\beta)$ of 2.8 and a dust opacity at $250 \mathrm{GHz}$ of $1 \mathrm{~g} \mathrm{~cm}^{-2}$. The values of $N\left(\mathrm{H}_{2}\right)$ and $\beta$ were adjusted so that the continuum observed with HIFI towards that source is reproduced well by our model.

The external layer has the same $\mathrm{H}_{2}$ column density, so that the total column density is $1.3 \times 10^{23} \mathrm{~cm}^{-2}$ or 140 mag of visual extinction. We modelled the emergent telescope-convolved spectrum of all the observed transitions of ammonia, by solving the radiative transfer with the Monte-Carlo code RATRAN (Hogerheijde \& van der Tak 2000). The collisional rates for $\mathrm{NH}_{3}-\mathrm{H}_{2}(\mathrm{p})$ are taken from Maret et al. (2009). The o/p of $\mathrm{NH}_{3}$ was fixed at 0.7 , as predicted by our chemistry model. The free parameters are the density, the gas temperature, and the $\mathrm{NH}_{3}$ column density in the external, absorbing, layer. The radii are set by the $\mathrm{H}_{2}$ column density and the density of that layer. The emergent spectra were then fitted simultaneously to match the observed ones, and a $\chi^{2}$ used to select the best-fit model. We found that the self-absorbed profile of the 1-0 transition tightly constrains the $\mathrm{H}_{2}$ density in the outer layer to less than $10^{4} \mathrm{~cm}^{-3}$, since for higher densities the predicted profile no longer shows absorption. As a result, the absorbing ammonia molecules reside in the most external layer of the circumbinary envelope of IRAS 16293-2422.

An ensemble of solutions is then found for the ammonia column density and the kinetic temperature, with the best agreement corresponding to $N\left(\mathrm{NH}_{3}\right)=1.4 \times 10^{15} \mathrm{~cm}^{-2}$ and $T=11 \mathrm{~K}$, respectively (see Fig. A.1). This column density is a factor of 2.5 below the lower limit of Hily-Blant et al. (2010a). A cross-check of the best agreement was performed by computing the emergent hyperfine spectra of NH. To this aim, we used the LIME radiative transfer code (Brinch \& Hogerheijde 2010), which takes line blending into account. The collisional rates for $\mathrm{NH}-\mathrm{H}_{2}(\mathrm{p})$ are scaled from the NH-He rates of Dumouchel et al. (2012) by applying the standard reduced mass ratio of 1.33 . The model that best reproduces the three hyperfine multiplets of $\mathrm{NH}$ (see Fig. A.2) has a column density of $\mathrm{NH}$ in the foreground layer of $2.0 \times 10^{14} \mathrm{~cm}^{-2}$, in excellent agreement with the determination of Bacmann et al. (2010) based on the "HFS" method of the CLASS software. Therefore this simple 2-layers model succesfully reproduces both the $\mathrm{NH}$ and $\mathrm{NH}_{3}$ spectra. The $\mathrm{NH}_{2}$ (o) column density was not re-analysed owing to the lack of collisional rates. However, the column density of $\mathrm{NH}_{2}(\mathrm{o})$ was derived by Hily-Blant et al. (2010a) using the same method and under the same assumptions as those for NH by Bacmann et al. (2010), and is thus expected to be reliable as well. In addition, here, we assumed an $\mathrm{o} / \mathrm{p}\left(\mathrm{NH}_{2}\right)$ of 2 to estimate the total column density of $\mathrm{NH}_{2}$. 
R. Le Gal et al.: Interstellar chemistry of nitrogen hydrides in dark clouds
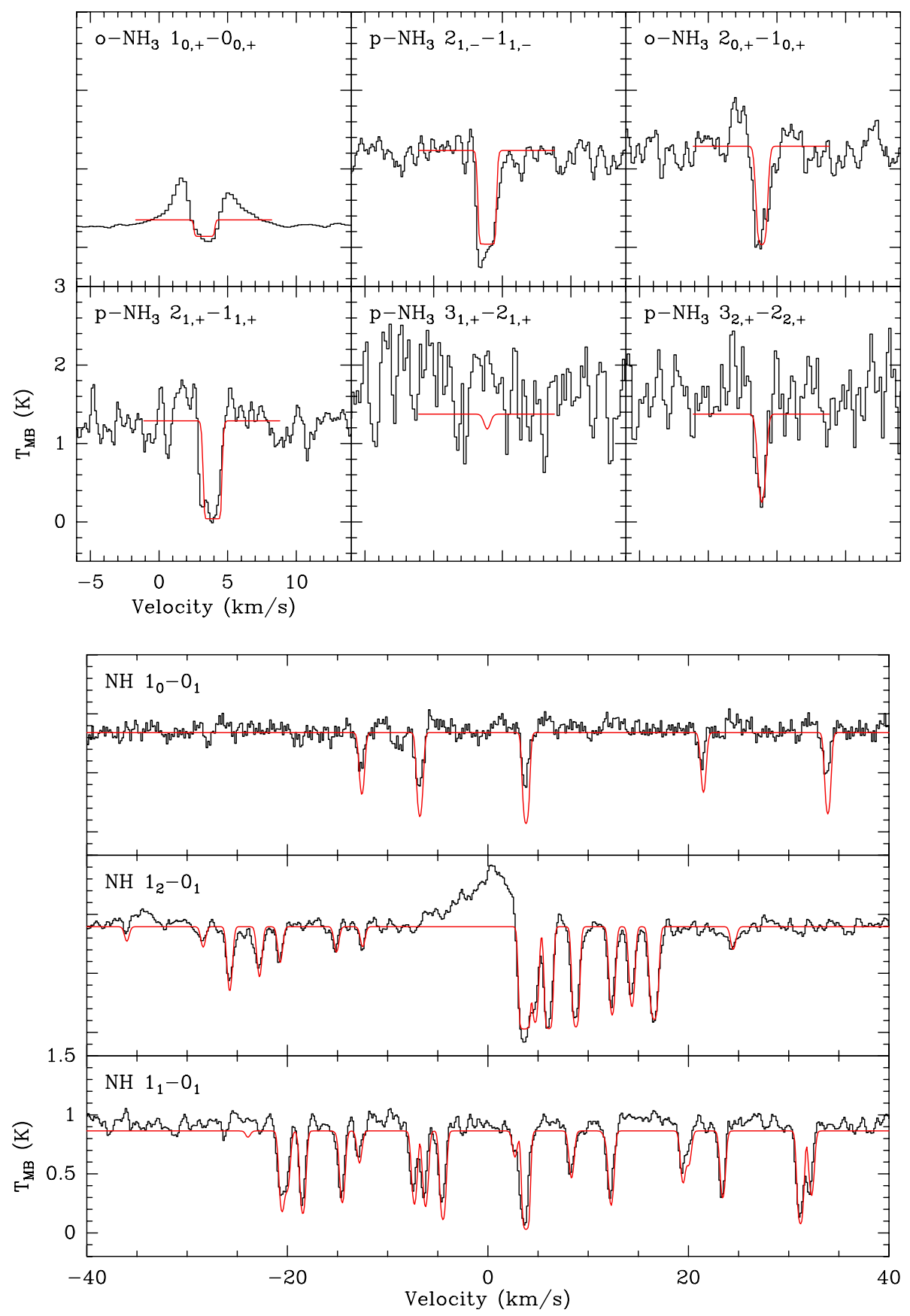

Fig. A.1. Comparison between the observed $\mathrm{NH}_{3}$ spectrum (black) from Hily-Blant et al. (2010a) and the best-fit model (red). The + and - signs in the transition labelling are the same as in Maret et al. (2009).

Fig. A.2. Same as in Fig. A.1 for the NH multiplets, using the same physical model as for $\mathrm{NH}_{3}$ and adopting a single $\mathrm{NH}$ column density of $2.2 \pm 0.8 \times 10^{14} \mathrm{~cm}^{-2}$. 


\section{Appendix B: Chemical updates}

Table B.1. New ion-neutral chemical reaction rates and ortho-para branching ratios.

\begin{tabular}{|c|c|c|c|c|c|c|c|c|c|c|}
\hline \multicolumn{5}{|c|}{ Chemical reactions $^{a}$} & $\begin{array}{c}\alpha \\
\mathrm{cm}^{3} \mathrm{~s}^{-1} \\
\end{array}$ & $\beta$ & \multirow[t]{2}{*}{$\gamma$} & \multirow[t]{2}{*}{$\begin{array}{c}k^{b} \\
\mathrm{~cm}^{3} \mathrm{~s}^{-1} \\
\end{array}$} & \multirow[t]{2}{*}{ References } & \multirow[t]{2}{*}{$N S B R^{c}$} \\
\hline \multicolumn{7}{|c|}{ Formation of $\mathrm{H}_{3}^{+}$} & & & & \\
\hline $\mathrm{H}_{2}^{+}(\mathrm{o})$ & $\mathrm{H}_{2}(\mathrm{o})$ & $\rightarrow$ & $\mathrm{H}_{3}^{+}(\mathrm{o})$ & $\mathrm{H}$ & $1.40(-9)$ & 0.00 & 0.00 & $1.40(-9)$ & 1 & $2 / 3$ \\
\hline $\mathrm{H}_{2}^{+}(\mathrm{o})$ & $\mathrm{H}_{2}(\mathrm{o})$ & $\rightarrow$ & $\mathrm{H}_{3}^{+}(\mathrm{p})$ & $\mathrm{H}$ & $7.00(-10)$ & 0.00 & 0.00 & $7.00(-10)$ & 1 & $1 / 3$ \\
\hline $\mathrm{H}_{2}^{+}(\mathrm{o})$ & $\mathrm{H}_{2}(\mathrm{p})$ & $\rightarrow$ & $\mathrm{H}_{3}^{+}(\mathrm{o})$ & $\mathrm{H}$ & $7.00(-10)$ & 0.00 & 0.00 & $7.00(-10)$ & 1 & $1 / 3$ \\
\hline $\mathrm{H}_{2}^{+}(\mathrm{o})$ & $\mathrm{H}_{2}(\mathrm{p})$ & $\rightarrow$ & $\mathrm{H}_{3}^{+}(\mathrm{p})$ & $\mathrm{H}$ & $1.40(-9)$ & 0.00 & 0.00 & $1.40(-9)$ & 1 & $2 / 3$ \\
\hline $\mathrm{H}_{2}^{+}(\mathrm{p})$ & $\mathrm{H}_{2}(\mathrm{o})$ & $\rightarrow$ & $\mathrm{H}_{3}^{+}(\mathrm{o})$ & $\mathrm{H}$ & $7.00(-10)$ & 0.00 & 0.00 & $7.00(-10)$ & 1 & $1 / 3$ \\
\hline $\mathrm{H}_{2}^{+}(\mathrm{p})$ & $\mathrm{H}_{2}(\mathrm{o})$ & $\rightarrow$ & $\mathrm{H}_{3}^{+}(\mathrm{p})$ & $\mathrm{H}$ & $1.40(-9)$ & 0.00 & 0.00 & $1.40(-9)$ & 1 & $2 / 3$ \\
\hline $\mathrm{H}_{2}^{+}(\mathrm{p})$ & $\mathrm{H}_{2}(\mathrm{p})$ & $\rightarrow$ & $\mathrm{H}_{3}^{+}(\mathrm{p})$ & $\mathrm{H}$ & $2.10(-9)$ & 0.00 & 0.00 & $2.10(-9)$ & 1 & 1 \\
\hline \multicolumn{11}{|c|}{ Main ortho-to-para conversion reactions of $\mathrm{H}_{2}$} \\
\hline $\mathrm{H}_{3}^{+}(\mathrm{o})$ & $\mathrm{H}_{2}(\mathrm{o})$ & $\rightarrow$ & $\mathrm{H}_{3}^{+}(\mathrm{o})$ & $\mathrm{H}_{2}(\mathrm{p})$ & $9.67(-11)$ & 0.00 & -0.14 & $9.81(-11)$ & 2 & \\
\hline $\mathrm{H}_{3}^{+}(\mathrm{o})$ & $\mathrm{H}_{2}(\mathrm{o})$ & $\rightarrow$ & $\mathrm{H}_{3}^{+}(\mathrm{p})$ & $\mathrm{H}_{2}(\mathrm{o})$ & $4.00(-10)$ & 0.00 & -0.19 & $4.08(-10)$ & 2 & \\
\hline $\mathrm{H}_{3}^{+}(\mathrm{o})$ & $\mathrm{H}_{2}(\mathrm{o})$ & $\rightarrow$ & $\mathrm{H}_{3}^{+}(\mathrm{p})$ & $\mathrm{H}_{2}(\mathrm{p})$ & $1.04(-10)$ & 0.00 & -0.14 & $1.04(-10)$ & 2 & \\
\hline $\mathrm{H}_{3}^{+}(\mathrm{o})$ & $\mathrm{H}_{2}(\mathrm{p})$ & $\rightarrow$ & $\mathrm{H}_{3}^{+}(\mathrm{o})$ & $\mathrm{H}_{2}(\mathrm{o})$ & $8.84(-10)$ & 0.00 & 170 & $3.66(-17)$ & 2 & \\
\hline $\mathrm{H}_{3}^{+}(\mathrm{o})$ & $\mathrm{H}_{2}(\mathrm{p})$ & $\rightarrow$ & $\mathrm{H}_{3}^{+}(\mathrm{p})$ & $\mathrm{H}_{2}(\mathrm{o})$ & $1.50(-9)$ & 0.00 & 136.2 & $1.82(-15)$ & 2 & \\
\hline $\mathrm{H}_{3}^{+}(\mathrm{p})$ & $\mathrm{H}_{2}(\mathrm{o})$ & $\rightarrow$ & $\mathrm{H}_{3}^{+}(\mathrm{o})$ & $\mathrm{H}_{2}(\mathrm{o})$ & $8.03(-10)$ & 0.00 & 32.6 & $3.08(-11)$ & 2 & \\
\hline $\mathrm{H}_{3}^{+}(\mathrm{p})$ & $\mathrm{H}_{2}(\mathrm{o})$ & $\rightarrow$ & $\mathrm{H}_{3}^{+}(\mathrm{o})$ & $\mathrm{H}_{2}(\mathrm{p})$ & $3.46(-10)$ & 0.00 & -0.69 & $3.71(-10)$ & 2 & \\
\hline $\mathrm{H}_{3}^{+}(\mathrm{p})$ & $\mathrm{H}_{2}(\mathrm{o})$ & $\rightarrow$ & $\mathrm{H}_{3}^{+}(\mathrm{p})$ & $\mathrm{H}_{2}(\mathrm{p})$ & $2.98(-10)$ & 0.00 & -0.69 & $3.19(-10)$ & 2 & \\
\hline $\mathrm{H}_{3}^{+}(\mathrm{p})$ & $\mathrm{H}_{2}(\mathrm{p})$ & $\rightarrow$ & $\mathrm{H}_{3}^{+}(\mathrm{p})$ & $\mathrm{H}_{2}(\mathrm{p})$ & $5.88(-10)$ & 0.00 & 198.2 & $1.45(-18)$ & 2 & \\
\hline $\mathrm{H}_{3}^{+}(\mathrm{p})$ & $\mathrm{H}_{2}(\mathrm{p})$ & $\rightarrow$ & $\mathrm{H}_{3}^{+}(\mathrm{p})$ & $\mathrm{H}_{2}(\mathrm{p})$ & $8.16(-10)$ & 0.00 & 164.9 & $5.63(-17)$ & 2 & \\
\hline $\mathrm{H}^{+}$ & $\mathrm{H}_{2}(\mathrm{o})$ & $\rightarrow$ & $\mathrm{H}^{+}$ & $\mathrm{H}_{2}(\mathrm{p})$ & $1.82(-10)$ & 0.13 & -0.02 & $1.17(-10)$ & 3 & \\
\hline $\mathrm{H}^{+}$ & $\mathrm{H}_{2}(\mathrm{p})$ & $\rightarrow$ & $\mathrm{H}^{+}$ & $\mathrm{H}_{2}(\mathrm{o})$ & $1.64(-9)$ & 0.13 & 170.5 & $4.15(-17)$ & 3 & \\
\hline $\mathrm{HCO}^{+}$ & $\mathrm{H}_{2}(\mathrm{o})$ & $\rightarrow$ & $\mathrm{HCO}^{+}$ & $\mathrm{H}_{2}(\mathrm{p})$ & $1.27(-10)$ & 0.00 & 0.00 & $1.27(-10)$ & 4 & \\
\hline $\mathrm{HCO}^{+}$ & $\mathrm{H}_{2}(\mathrm{p})$ & $\rightarrow$ & $\mathrm{HCO}^{+}$ & $\mathrm{H}_{2}(\mathrm{o})$ & $1.14(-9)$ & 0.00 & 170.5 & $4.49(-17)$ & 4 & \\
\hline \multicolumn{11}{|c|}{ Nitrogen hydrides formation } \\
\hline $\mathrm{N}^{+}$ & $\mathrm{H}_{2}(\mathrm{o})$ & $\rightarrow$ & $\mathrm{NH}^{+}$ & $\mathrm{H}$ & $4.20(-10)$ & -0.15 & 44.1 & $8.50(-12)$ & 5 & \\
\hline $\mathrm{N}^{+}$ & $\mathrm{H}_{2}(\mathrm{p})$ & $\rightarrow$ & $\mathrm{NH}^{+}$ & $\mathrm{H}$ & $8.35(-10)$ & 0.00 & 168.5 & $4.02(-17)$ & 5 & \\
\hline $\mathrm{NH}^{+}$ & $\mathrm{H}_{2}(\mathrm{o})$ & $\rightarrow$ & $\mathrm{NH}_{2}^{+}(\mathrm{o})$ & $\mathrm{H}$ & $1.06(-9)$ & 0.00 & 0.00 & $1.06(-9)$ & 6 & $5 / 6$ \\
\hline $\mathrm{NH}^{+}$ & $\mathrm{H}_{2}(\mathrm{o})$ & $\rightarrow$ & $\mathrm{NH}_{2}^{+}(\mathrm{p})$ & $\mathrm{H}$ & $2.13(-10)$ & 0.00 & 0.00 & $2.13(-10)$ & 6 & $1 / 6$ \\
\hline $\mathrm{NH}^{+}$ & $\mathrm{H}_{2}(\mathrm{p})$ & $\rightarrow$ & $\mathrm{NH}_{2}^{+}(\mathrm{o})$ & $\mathrm{H}$ & $6.38(-10)$ & 0.00 & 0.00 & $6.38(-10)$ & 6 & $1 / 2$ \\
\hline $\mathrm{NH}^{+}$ & $\mathrm{H}_{2}(\mathrm{p})$ & $\rightarrow$ & $\mathrm{NH}_{2}^{+}(\mathrm{p})$ & $\mathrm{H}$ & $6.38(-10)$ & 0.00 & 0.00 & $6.38(-10)$ & 6 & $1 / 2$ \\
\hline $\mathrm{NH}_{2}^{+}(\mathrm{o})$ & $\mathrm{H}_{2}(\mathrm{o})$ & $\rightarrow$ & $\mathrm{NH}_{3}^{+}(\mathrm{o})$ & $\mathrm{H}$ & $1.80(-10)$ & 0.00 & 0.00 & $1.80(-10)$ & 6 & $2 / 3$ \\
\hline $\mathrm{NH}_{2}^{+}(\mathrm{o})$ & $\mathrm{H}_{2}(\mathrm{o})$ & $\rightarrow$ & $\mathrm{NH}_{3}^{+}(\mathrm{p})$ & $\mathrm{H}$ & $9.00(-11)$ & 0.00 & 0.00 & $9.00(-11)$ & 6 & $1 / 3$ \\
\hline $\mathrm{NH}_{2}^{+}(\mathrm{o})$ & $\mathrm{H}_{2}(\mathrm{p})$ & $\rightarrow$ & $\mathrm{NH}_{3}^{+}(\mathrm{o})$ & $\mathrm{H}$ & $9.00(-11)$ & 0.00 & 0.00 & $9.00(-11)$ & 6 & $1 / 3$ \\
\hline $\mathrm{NH}_{2}^{+}(\mathrm{o})$ & $\mathrm{H}_{2}(\mathrm{p})$ & $\rightarrow$ & $\mathrm{NH}_{3}^{+}(\mathrm{p})$ & $\mathrm{H}$ & $1.80(-10)$ & 0.00 & 0.00 & $1.80(-10)$ & 6 & $2 / 3$ \\
\hline $\mathrm{NH}_{2}^{+}(\mathrm{p})$ & $\mathrm{H}_{2}(\mathrm{o})$ & $\rightarrow$ & $\mathrm{NH}_{3}^{+}(\mathrm{o})$ & $\mathrm{H}$ & $9.00(-11)$ & 0.00 & 0.00 & $9.00(-11)$ & 6 & $1 / 3$ \\
\hline $\mathrm{NH}_{2}^{+}(\mathrm{p})$ & $\mathrm{H}_{2}(\mathrm{o})$ & $\rightarrow$ & $\mathrm{NH}_{3}^{+}(\mathrm{p})$ & $\mathrm{H}$ & $1.80(-10)$ & 0.00 & 0.00 & $1.80(-10)$ & 6 & $2 / 3$ \\
\hline $\mathrm{NH}_{2}^{+}(\mathrm{p})$ & $\mathrm{H}_{2}(\mathrm{p})$ & $\rightarrow$ & $\mathrm{NH}_{3}^{+}(\mathrm{p})$ & $\mathrm{H}$ & $2.70(-10)$ & 0.00 & 0.00 & $2.70(-10)$ & 6 & 1 \\
\hline $\mathrm{NH}_{3}^{+}(\mathrm{o})$ & $\mathrm{H}_{2}(\mathrm{o})$ & $\rightarrow$ & $\mathrm{NH}_{4}^{+}(I=2)$ & $\mathrm{H}$ & $1.40(-12)$ & 0.00 & 0.00 & $1.40(-12)$ & 6 & $7 / 12$ \\
\hline $\mathrm{NH}_{3}^{+}(\mathrm{o})$ & $\mathrm{H}_{2}(\mathrm{o})$ & $\rightarrow$ & $\mathrm{NH}_{4}^{+}(I=1)$ & $\mathrm{H}$ & $8.40(-13)$ & 0.00 & 0.00 & $8.40(-13)$ & 6 & $21 / 60$ \\
\hline $\mathrm{NH}_{3}^{+}(\mathrm{o})$ & $\mathrm{H}_{2}(\mathrm{o})$ & $\rightarrow$ & $\mathrm{NH}_{4}^{+}(I=0)$ & $\mathrm{H}$ & $1.60(-13)$ & 0.00 & 0.00 & $1.60(-13)$ & 6 & $1 / 15$ \\
\hline $\mathrm{NH}_{3}^{+}(\mathrm{o})$ & $\mathrm{H}_{2}(\mathrm{p})$ & $\rightarrow$ & $\mathrm{NH}_{4}^{+}(I=2)$ & $\mathrm{H}$ & $1.80(-12)$ & 0.00 & 0.00 & $1.80(-12)$ & 6 & $1 / 4$ \\
\hline $\mathrm{NH}_{3}^{+}(\mathrm{o})$ & $\mathrm{H}_{2}(\mathrm{p})$ & $\rightarrow$ & $\mathrm{NH}_{4}^{+}(I=1)$ & $\mathrm{H}$ & $6.00(-13)$ & 0.00 & 0.00 & $6.00(-13)$ & 6 & $3 / 4$ \\
\hline $\mathrm{NH}_{3}^{+}(\mathrm{o})$ & $\mathrm{H}_{2}(\mathrm{p})$ & $\rightarrow$ & $\mathrm{NH}_{4}^{+}(I=0)$ & $\mathrm{H}$ & 0.00 & 0.00 & 0.00 & 0.00 & 6 & 0 \\
\hline $\mathrm{NH}_{3}^{+}(\mathrm{p})$ & $\mathrm{H}_{2}(\mathrm{o})$ & $\rightarrow$ & $\mathrm{NH}_{4}^{+}(I=2)$ & $\mathrm{H}$ & $4.00(-13)$ & 0.00 & 0.00 & $4.00(-13)$ & 6 & $1 / 6$ \\
\hline
\end{tabular}

Notes. Numbers in parentheses are power of $10 \cdot^{(a)} \mathrm{o}$ and $\mathrm{p}$ stand for ortho and para states respectively. As a spherical top with four identical protons, the ammonium ion exists in three nuclear spin states noted as in Faure et al. (2013): para $(I=0)$, meta $(I=2)$, and ortho $(I=1)$. We note that the meta and ortho species are inverted in Rist et al. (2013). ${ }^{(b)}$ Rates $k=\alpha(T / 300)^{\beta} \exp (-\gamma / T)$ have been computed for a $10 \mathrm{~K}$ temperature. (c) NSBR stands for nuclear-spin branching ratio. These were combined with the overall rate coefficients taken from the cited references, e.g. Prasad \& Huntress (1980). The integer ratios like e.g. 28/5/12 are normalized NSBR and stand for (28/5)/12 i.e. 28/60.

References. (1) Langevin rate: $2.10 \times 10^{-9} \mathrm{~cm}^{3} \mathrm{~s}^{-1}$; (2) Hugo et al. (2009); (3) Honvault et al. (2011); (4) Langevin rate: 1.52 $\times 10^{-9} \mathrm{~cm}^{3} \mathrm{~s}^{-1}$; (5) Dislaire et al (2012); (6) Anicich \& Huntress (1986); (7) Prasad \& Huntress (1980); (8) Marquette et al. (1989); (9) datasheet by Ian Smith from KIDA (Wakelam et al. 2012). 
Table B.1. continued.

\begin{tabular}{|c|c|c|c|c|c|c|c|c|c|c|}
\hline \multicolumn{5}{|c|}{ Chemical reactions $^{a}$} & \multirow{2}{*}{$\begin{array}{c}\begin{array}{c}\alpha \\
\mathrm{cm}^{3} \mathrm{~s}^{-1}\end{array} \\
1.68(-12)\end{array}$} & \multirow{2}{*}{$\begin{array}{c}\beta \\
0.00\end{array}$} & \multirow{2}{*}{$\begin{array}{c}\gamma \\
0.00\end{array}$} & \multirow{2}{*}{$\begin{array}{c}k^{b} \\
\mathrm{~cm}^{3} \mathrm{~s}^{-1} \\
1.68(-12)\end{array}$} & \multirow{2}{*}{$\begin{array}{c}\text { References } \\
6\end{array}$} & \multirow{2}{*}{$\begin{array}{r}N_{S B R^{c}} \\
21 / 30\end{array}$} \\
\hline $\mathrm{NH}_{3}^{+}(\mathrm{p})$ & $\mathrm{H}_{2}(\mathrm{o})$ & $\rightarrow$ & $\mathrm{NH}_{4}^{+}(I=1)$ & $\mathrm{H}$ & & & & & & \\
\hline $\mathrm{NH}_{3}^{+}(\mathrm{p})$ & $\mathrm{H}_{2}(\mathrm{o})$ & $\rightarrow$ & $\mathrm{NH}_{4}^{+}(I=0)$ & $\mathrm{H}$ & $3.20(-13)$ & 0.00 & 0.00 & $3.20(-13)$ & 6 & $2 / 15$ \\
\hline $\mathrm{NH}_{3}^{+}(\mathrm{p})$ & $\mathrm{H}_{2}(\mathrm{p})$ & $\rightarrow$ & $\mathrm{NH}_{4}^{+}(I=2)$ & $\mathrm{H}$ & 0.00 & 0.00 & 0.00 & 0.00 & 6 & 0 \\
\hline $\mathrm{NH}_{3}^{+}(\mathrm{p})$ & $\mathrm{H}_{2}(\mathrm{p})$ & $\rightarrow$ & $\mathrm{NH}_{4}^{+}(I=1)$ & $\mathrm{H}$ & $1.44(-12)$ & 0.00 & 0.00 & $1.44(-12)$ & 6 & $3 / 5$ \\
\hline $\mathrm{NH}_{3}^{+}(\mathrm{p})$ & $\mathrm{H}_{2}(\mathrm{p})$ & $\rightarrow$ & $\mathrm{NH}_{4}^{+}(I=0)$ & $\mathrm{H}$ & $9.60(-13)$ & 0.00 & 0.00 & $9.60(-13)$ & 6 & $2 / 5$ \\
\hline \multicolumn{11}{|c|}{ Destruction of nitrogen hydrides by $\mathrm{H}_{3}^{+}, \mathrm{HCO}^{+}$, and $\mathrm{N}_{2} \mathrm{H}^{+}$} \\
\hline $\mathrm{H}_{3}^{+}(\mathrm{p})$ & $\mathrm{NH}$ & $\rightarrow$ & $\mathrm{NH}_{2}^{+}(\mathrm{p})$ & $\mathrm{H}_{2}(\mathrm{p})$ & $1.63(-10)$ & 0.00 & 0.00 & $1.63(-10)$ & 7 & $1 / 8$ \\
\hline $\mathrm{H}_{3}^{+}(\mathrm{p})$ & $\mathrm{NH}$ & $\rightarrow$ & $\mathrm{NH}_{2}^{+}(\mathrm{o})$ & $\mathrm{H}_{2}(\mathrm{p})$ & $3.25(-10)$ & 0.00 & 0.00 & $3.25(-10)$ & 7 & $1 / 4$ \\
\hline $\mathrm{H}_{3}^{+}(\mathrm{p})$ & NH & $\rightarrow$ & $\mathrm{NH}_{2}^{+}(\mathrm{p})$ & $\mathrm{H}_{2}(\mathrm{o})$ & $3.25(-10)$ & 0.00 & 0.00 & $3.25(-10)$ & 7 & $1 / 4$ \\
\hline $\mathrm{H}_{3}^{+}(\mathrm{p})$ & $\mathrm{NH}$ & $\rightarrow$ & $\mathrm{NH}_{2}^{+}(\mathrm{o})$ & $\mathrm{H}_{2}(\mathrm{o})$ & $4.88(-10)$ & 0.00 & 0.00 & $4.88(-10)$ & 7 & $3 / 8$ \\
\hline $\mathrm{H}_{3}^{+}(\mathrm{p})$ & $\mathrm{NH}_{2}(\mathrm{p})$ & $\rightarrow$ & $\mathrm{NH}_{3}^{+}(\mathrm{p})$ & $\mathrm{H}_{2}(\mathrm{p})$ & $7.20(-10)$ & 0.00 & 0.00 & $7.20(-10)$ & 7 & $8 / 5 / 4$ \\
\hline $\mathrm{H}_{3}^{+}(\mathrm{p})$ & $\mathrm{NH}_{2}(\mathrm{p})$ & $\rightarrow$ & $\mathrm{NH}_{3}^{+}(\mathrm{p})$ & $\mathrm{H}_{2}(\mathrm{o})$ & $7.20(-10)$ & 0.00 & 0.00 & $7.20(-10)$ & 7 & $8 / 5 / 4$ \\
\hline $\mathrm{H}_{3}^{+}(\mathrm{p})$ & $\mathrm{NH}_{2}(\mathrm{p})$ & $\rightarrow$ & $\mathrm{NH}_{3}^{+}(\mathrm{o})$ & $\mathrm{H}_{2}(\mathrm{o})$ & $3.60(-10)$ & 0.00 & 0.00 & $3.60(-10)$ & 7 & $4 / 5 / 4$ \\
\hline $\mathrm{H}_{3}^{+}(\mathrm{p})$ & $\mathrm{NH}_{2}(\mathrm{o})$ & $\rightarrow$ & $\mathrm{NH}_{3}^{+}(\mathrm{p})$ & $\mathrm{H}_{2}(\mathrm{o})$ & $8.40(-10)$ & 0.00 & 0.00 & $8.40(-10)$ & 7 & $28 / 5 / 12$ \\
\hline $\mathrm{H}_{3}^{+}(\mathrm{p})$ & $\mathrm{NH}_{2}(\mathrm{o})$ & $\rightarrow$ & $\mathrm{NH}_{3}^{+}(\mathrm{o})$ & $\mathrm{H}_{2}(\mathrm{o})$ & $4.20(-10)$ & 0.00 & 0.00 & $4.20(-10)$ & 7 & $14 / 5 / 12$ \\
\hline $\mathrm{H}_{3}^{+}(\mathrm{p})$ & $\mathrm{NH}_{2}(\mathrm{o})$ & $\rightarrow$ & $\mathrm{NH}_{3}^{+}(\mathrm{p})$ & $\mathrm{H}_{2}(\mathrm{p})$ & $2.40(-10)$ & 0.00 & 0.00 & $2.40(-10)$ & 7 & $8 / 5 / 12$ \\
\hline $\mathrm{H}_{3}^{+}(\mathrm{p})$ & $\mathrm{NH}_{2}(\mathrm{o})$ & $\rightarrow$ & $\mathrm{NH}_{3}^{+}(\mathrm{o})$ & $\mathrm{H}_{2}(\mathrm{p})$ & $3.00(-10)$ & 0.00 & 0.00 & $3.00(-10)$ & 7 & $2 / 12$ \\
\hline $\mathrm{H}_{3}^{+}(\mathrm{p})$ & $\mathrm{NH}_{3}(\mathrm{p})$ & $\rightarrow$ & $\mathrm{NH}_{4}^{+}(I=0)$ & $\mathrm{H}_{2}(\mathrm{p})$ & $9.10(-10)$ & 0.00 & 0.00 & $9.10(-10)$ & 8 & $8 / 5 / 16$ \\
\hline $\mathrm{H}_{3}^{+}(\mathrm{p})$ & $\mathrm{NH}_{3}(\mathrm{p})$ & $\rightarrow$ & $\mathrm{NH}_{4}^{+}(I=1)$ & $\mathrm{H}_{2}(\mathrm{p})$ & $2.28(-9)$ & 0.00 & 0.00 & $2.28(-9)$ & 8 & $4 / 16$ \\
\hline $\mathrm{H}_{3}^{+}(\mathrm{p})$ & $\mathrm{NH}_{3}(\mathrm{p})$ & $\rightarrow$ & $\mathrm{NH}_{4}^{+}(I=0)$ & $\mathrm{H}_{2}(\mathrm{o})$ & $1.52(-9)$ & 0.00 & 0.00 & $1.52(-9)$ & 8 & $8 / 3 / 16$ \\
\hline $\mathrm{H}_{3}^{+}(\mathrm{p})$ & $\mathrm{NH}_{3}(\mathrm{p})$ & $\rightarrow$ & $\mathrm{NH}_{4}^{+}(I=1)$ & $\mathrm{H}_{2}(\mathrm{o})$ & $3.64(-9)$ & 0.00 & 0.00 & $3.64(-9)$ & 8 & $32 / 5 / 16$ \\
\hline $\mathrm{H}_{3}^{+}(\mathrm{p})$ & $\mathrm{NH}_{3}(\mathrm{p})$ & $\rightarrow$ & $\mathrm{NH}_{4}^{+}(I=2)$ & $\mathrm{H}_{2}(\mathrm{o})$ & $7.58(-10)$ & 0.00 & 0.00 & $7.58(-10)$ & 8 & $4 / 3 / 16$ \\
\hline $\mathrm{H}_{3}^{+}(\mathrm{p})$ & $\mathrm{NH}_{3}(\mathrm{o})$ & $\rightarrow$ & $\mathrm{NH}_{4}^{+}(I=0)$ & $\mathrm{H}_{2}(\mathrm{o})$ & $7.58(-10)$ & 0.00 & 0.00 & $7.58(-10)$ & 8 & $4 / 3 / 16$ \\
\hline $\mathrm{H}_{3}^{+}(\mathrm{p})$ & $\mathrm{NH}_{3}(\mathrm{o})$ & $\rightarrow$ & $\mathrm{NH}_{4}^{+}(I=1)$ & $\mathrm{H}_{2}(\mathrm{o})$ & $4.55(-9)$ & 0.00 & 0.00 & $4.55(-9)$ & 8 & $8 / 16$ \\
\hline $\mathrm{H}_{3}^{+}(\mathrm{p})$ & $\mathrm{NH}_{3}(\mathrm{o})$ & $\rightarrow$ & $\mathrm{NH}_{4}^{+}(I=2)$ & $\mathrm{H}_{2}(\mathrm{o})$ & $1.52(-9)$ & 0.00 & 0.00 & $1.52(-9)$ & 8 & $8 / 3 / 16$ \\
\hline $\mathrm{H}_{3}^{+}(\mathrm{p})$ & $\mathrm{NH}_{3}(\mathrm{o})$ & $\rightarrow$ & $\mathrm{NH}_{4}^{+}(I=2)$ & $\mathrm{H}_{2}(\mathrm{p})$ & $1.14(-9)$ & 0.00 & 0.00 & $1.14(-9)$ & 8 & $2 / 16$ \\
\hline $\mathrm{H}_{3}^{+}(\mathrm{p})$ & $\mathrm{NH}_{3}(\mathrm{o})$ & $\rightarrow$ & $\mathrm{NH}_{4}^{+}(I=1)$ & $\mathrm{H}_{2}(\mathrm{p})$ & $1.14(-9)$ & 0.00 & 0.00 & $1.14(-9)$ & 8 & $2 / 16$ \\
\hline $\mathrm{H}_{3}^{+}(\mathrm{o})$ & $\mathrm{NH}$ & $\rightarrow$ & $\mathrm{NH}_{2}^{+}(\mathrm{p})$ & $\mathrm{H}_{2}(\mathrm{o})$ & $1.63(-10)$ & 0.00 & 0.00 & $1.63(-10)$ & 7 & $1 / 8$ \\
\hline $\mathrm{H}_{3}^{+}(\mathrm{o})$ & $\mathrm{NH}$ & $\rightarrow$ & $\mathrm{NH}_{2}^{+}(\mathrm{o})$ & $\mathrm{H}_{2}(\mathrm{o})$ & $9.75(-10)$ & 0.00 & 0.00 & $9.75(-10)$ & 7 & $6 / 8$ \\
\hline $\mathrm{H}_{3}^{+}(\mathrm{o})$ & $\mathrm{NH}$ & $\rightarrow$ & $\mathrm{NH}_{2}^{+}(\mathrm{o})$ & $\mathrm{H}_{2}(\mathrm{p})$ & $1.63(-10)$ & 0.00 & 0.00 & $1.63(-10)$ & 7 & $1 / 8$ \\
\hline $\mathrm{H}_{3}^{+}(\mathrm{o})$ & $\mathrm{NH}_{2}(\mathrm{p})$ & $\rightarrow$ & $\mathrm{NH}_{3}^{+}(\mathrm{o})$ & $\mathrm{H}_{2}(\mathrm{p})$ & $4.50(-10)$ & 0.00 & 0.00 & $4.50(-10)$ & 7 & $1 / 4$ \\
\hline $\mathrm{H}_{3}^{+}(\mathrm{o})$ & $\mathrm{NH}_{2}(\mathrm{p})$ & $\rightarrow$ & $\mathrm{NH}_{3}^{+}(\mathrm{p})$ & $\mathrm{H}_{2}(\mathrm{o})$ & $9.00(-10)$ & 0.00 & 0.00 & $9.00(-10)$ & 7 & $2 / 4$ \\
\hline $\mathrm{H}_{3}^{+}(\mathrm{o})$ & $\mathrm{NH}_{2}(\mathrm{p})$ & $\rightarrow$ & $\mathrm{NH}_{3}^{+}(\mathrm{o})$ & $\mathrm{H}_{2}(\mathrm{o})$ & $4.50(-10)$ & 0.00 & 0.00 & $4.50(-10)$ & 7 & $1 / 4$ \\
\hline $\mathrm{H}_{3}^{+}(\mathrm{o})$ & $\mathrm{NH}_{2}(\mathrm{o})$ & $\rightarrow$ & $\mathrm{NH}_{3}^{+}(\mathrm{p})$ & $\mathrm{H}_{2}(\mathrm{p})$ & $1.20(-10)$ & 0.00 & 0.00 & $1.20(-10)$ & 7 & $4 / 5 / 12$ \\
\hline $\mathrm{H}_{3}^{+}(\mathrm{o})$ & $\mathrm{NH}_{2}(\mathrm{o})$ & $\rightarrow$ & $\mathrm{NH}_{3}^{+}(\mathrm{p})$ & $\mathrm{H}_{2}(\mathrm{o})$ & $4.20(-10)$ & 0.00 & 0.00 & $4.20(-10)$ & 7 & $14 / 5 / 12$ \\
\hline $\mathrm{H}_{3}^{+}(\mathrm{o})$ & $\mathrm{NH}_{2}(\mathrm{o})$ & $\rightarrow$ & $\mathrm{NH}_{3}^{+}(\mathrm{o})$ & $\mathrm{H}_{2}(\mathrm{p})$ & $1.50(-10)$ & 0.00 & 0.00 & $1.50(-10)$ & 7 & $1 / 12$ \\
\hline $\mathrm{H}_{3}^{+}(\mathrm{o})$ & $\mathrm{NH}_{2}(\mathrm{o})$ & $\rightarrow$ & $\mathrm{NH}_{3}^{+}(\mathrm{o})$ & $\mathrm{H}_{2}(\mathrm{o})$ & $1.11(-9)$ & 0.00 & 0.00 & $1.11(-9)$ & 7 & $37 / 5 / 12$ \\
\hline $\mathrm{H}_{3}^{+}(\mathrm{o})$ & $\mathrm{NH}_{3}(\mathrm{p})$ & $\rightarrow$ & $\mathrm{NH}_{4}^{+}(I=1)$ & $\mathrm{H}_{2}(\mathrm{p})$ & $1.14(-9)$ & 0.00 & 0.00 & $1.14(-9)$ & 8 & $2 / 16$ \\
\hline $\mathrm{H}_{3}^{+}(\mathrm{o})$ & $\mathrm{NH}_{3}(\mathrm{p})$ & $\rightarrow$ & $\mathrm{NH}_{4}^{+}(I=2)$ & $\mathrm{H}_{2}(\mathrm{p})$ & $1.14(-9)$ & 0.00 & 0.00 & $1.14(-9)$ & 8 & $2 / 16$ \\
\hline $\mathrm{H}_{3}^{+}(\mathrm{o})$ & $\mathrm{NH}_{3}(\mathrm{p})$ & $\rightarrow$ & $\mathrm{NH}_{4}^{+}(I=0)$ & $\mathrm{H}_{2}(\mathrm{o})$ & $7.58(-10)$ & 0.00 & 0.00 & $7.58(-10)$ & 8 & $4 / 3 / 16$ \\
\hline $\mathrm{H}_{3}^{+}(\mathrm{o})$ & $\mathrm{NH}_{3}(\mathrm{p})$ & $\rightarrow$ & $\mathrm{NH}_{4}^{+}(I=1)$ & $\mathrm{H}_{2}(\mathrm{o})$ & $4.55(-9)$ & 0.00 & 0.00 & $4.55(-9)$ & 8 & $8 / 16$ \\
\hline $\mathrm{H}_{3}^{+}(\mathrm{o})$ & $\mathrm{NH}_{3}(\mathrm{p})$ & $\rightarrow$ & $\mathrm{NH}_{4}^{+}(I=2)$ & $\mathrm{H}_{2}(\mathrm{o})$ & $1.52(-9)$ & 0.00 & 0.00 & $1.52(-9)$ & 8 & $8 / 3 / 16$ \\
\hline $\mathrm{H}_{3}^{+}(\mathrm{o})$ & $\mathrm{NH}_{3}(\mathrm{o})$ & $\rightarrow$ & $\mathrm{NH}_{4}^{+}(I=0)$ & $\mathrm{H}_{2}(\mathrm{p})$ & $2.28(-10)$ & 0.00 & 0.00 & $2.28(-10)$ & 8 & $2 / 5 / 16$ \\
\hline $\mathrm{H}_{3}^{+}(\mathrm{o})$ & $\mathrm{NH}_{3}(\mathrm{o})$ & $\rightarrow$ & $\mathrm{NH}_{4}^{+}(I=1)$ & $\mathrm{H}_{2}(\mathrm{p})$ & $5.69(-10)$ & 0.00 & 0.00 & $5.69(-10)$ & 8 & $1 / 16$ \\
\hline $\mathrm{H}_{3}^{+}(\mathrm{o})$ & $\mathrm{NH}_{3}(\mathrm{o})$ & $\rightarrow$ & $\mathrm{NH}_{4}^{+}(I=2)$ & $\mathrm{H}_{2}(\mathrm{p})$ & $5.69(-10)$ & 0.00 & 0.00 & $5.69(-10)$ & 8 & $1 / 16$ \\
\hline $\mathrm{H}_{3}^{+}(\mathrm{o})$ & $\mathrm{NH}_{3}(\mathrm{o})$ & $\rightarrow$ & $\mathrm{NH}_{4}^{+}(I=0)$ & $\mathrm{H}_{2}(\mathrm{o})$ & $3.79(-10)$ & 0.00 & 0.00 & $3.79(-10)$ & 8 & $2 / 3 / 16$ \\
\hline $\mathrm{H}_{3}^{+}(\mathrm{o})$ & $\mathrm{NH}_{3}(\mathrm{o})$ & $\rightarrow$ & $\mathrm{NH}_{4}^{+}(I=1)$ & $\mathrm{H}_{2}(\mathrm{o})$ & $2.62(-9)$ & 0.00 & 0.00 & $2.62(-9)$ & 8 & $23 / 5 / 16$ \\
\hline $\mathrm{H}_{3}^{+}(\mathrm{o})$ & $\mathrm{NH}_{3}(\mathrm{o})$ & $\rightarrow$ & $\mathrm{NH}_{4}^{+}(I=2)$ & $\mathrm{H}_{2}(\mathrm{o})$ & $4.74(-9)$ & 0.00 & 0.00 & $4.74(-9)$ & 8 & $25 / 3 / 16$ \\
\hline $\mathrm{HCO}^{+}$ & $\mathrm{NH}$ & $\rightarrow$ & $\mathrm{NH}_{2}^{+}(\mathrm{p})$ & $\mathrm{CO}$ & $1.60(-10)$ & 0.00 & 0.00 & $1.60(-10)$ & 7 & $1 / 4$ \\
\hline $\mathrm{HCO}^{+}$ & $\mathrm{NH}$ & $\rightarrow$ & $\mathrm{NH}_{2}^{+}(\mathrm{o})$ & $\mathrm{CO}$ & $4.80(-10)$ & 0.00 & 0.00 & $4.80(-10)$ & 7 & $3 / 4$ \\
\hline $\mathrm{HCO}^{+}$ & $\mathrm{NH}_{2}(\mathrm{p})$ & $\rightarrow$ & $\mathrm{NH}_{3}^{+}(\mathrm{p})$ & $\mathrm{CO}$ & $8.90(-10)$ & 0.00 & 0.00 & $8.90(-10)$ & 7 & $1 / 1$ \\
\hline $\mathrm{HCO}^{+}$ & $\mathrm{NH}_{2}(\mathrm{o})$ & $\rightarrow$ & $\mathrm{NH}_{3}^{+}(\mathrm{p})$ & $\mathrm{CO}$ & $3.00(-10)$ & 0.00 & 0.00 & $3.00(-10)$ & 7 & $1 / 3$ \\
\hline $\mathrm{HCO}^{+}$ & $\mathrm{NH}_{2}(\mathrm{o})$ & $\rightarrow$ & $\mathrm{NH}_{3}^{+}(\mathrm{o})$ & $\mathrm{CO}$ & $5.90(-10)$ & 0.00 & 0.00 & $5.90(-10)$ & 7 & $2 / 3$ \\
\hline
\end{tabular}


A\&A 562, A83 (2014)

Table B.1. continued.

\begin{tabular}{|c|c|c|c|c|c|c|c|c|c|c|}
\hline \multicolumn{5}{|c|}{ Chemical reactions $^{a}$} & \multirow{2}{*}{$\begin{array}{c}\begin{array}{c}\alpha \\
\mathrm{cm}^{3} \mathrm{~s}^{-1}\end{array} \\
4.80(-10)\end{array}$} & \multirow{2}{*}{$\begin{array}{c}\beta \\
0.00\end{array}$} & \multirow{2}{*}{$\begin{array}{c}\gamma \\
0.00\end{array}$} & \multirow{2}{*}{$\begin{array}{c}\begin{array}{c}k^{b} \\
\mathrm{~cm}^{3} \mathrm{~s}^{-1}\end{array} \\
4.80(-10)\end{array}$} & \multirow{2}{*}{$\begin{array}{c}\text { References } \\
6\end{array}$} & \multirow{2}{*}{$\begin{array}{r}N S B R^{c} \\
1 / 4\end{array}$} \\
\hline $\mathrm{HCO}^{+}$ & $\mathrm{NH}_{3}(\mathrm{p})$ & $\rightarrow$ & $\mathrm{NH}_{4}^{+}(I=0)$ & $\mathrm{CO}$ & & & & & & \\
\hline $\mathrm{HCO}^{+}$ & $\mathrm{NH}_{3}(\mathrm{p})$ & $\rightarrow$ & $\mathrm{NH}_{4}^{+}(I=1)$ & $\mathrm{CO}$ & $1.40(-9)$ & 0.00 & 0.00 & $1.40(-9)$ & 6 & $3 / 4$ \\
\hline $\mathrm{HCO}^{+}$ & $\mathrm{NH}_{3}(\mathrm{o})$ & $\rightarrow$ & $\mathrm{NH}_{4}^{+}(I=1)$ & $\mathrm{CO}$ & $7.10(-10)$ & 0.00 & 0.00 & $7.10(-10)$ & 6 & $3 / 8$ \\
\hline $\mathrm{HCO}^{+}$ & $\mathrm{NH}_{3}(\mathrm{o})$ & $\rightarrow$ & $\mathrm{NH}_{4}^{+}(I=2)$ & $\mathrm{CO}$ & $1.20(-9)$ & 0.00 & 0.00 & $1.20(-9)$ & 6 & $5 / 8$ \\
\hline $\mathrm{N}_{2} \mathrm{H}^{+}$ & $\mathrm{NH}_{3}(\mathrm{p})$ & $\rightarrow$ & $\mathrm{NH}_{4}^{+}(I=0)$ & $\mathrm{N}_{2}$ & $5.75(-10)$ & 0.00 & 0.00 & $5.75(-10)$ & 6 & $1 / 4$ \\
\hline $\mathrm{N}_{2} \mathrm{H}^{+}$ & $\mathrm{NH}_{3}(\mathrm{p})$ & $\rightarrow$ & $\mathrm{NH}_{4}^{+}(I=1)$ & $\mathrm{N}_{2}$ & $1.73(-9)$ & 0.00 & 0.00 & $1.73(-9)$ & 6 & $3 / 4$ \\
\hline $\mathrm{N}_{2} \mathrm{H}^{+}$ & $\mathrm{NH}_{3}(\mathrm{o})$ & $\rightarrow$ & $\mathrm{NH}_{4}^{+}(I=2)$ & $\mathrm{N}_{2}$ & $8.63(-10)$ & 0.00 & 0.00 & $8.63(-10)$ & 6 & $3 / 8$ \\
\hline $\mathrm{N}_{2} \mathrm{H}^{+}$ & $\mathrm{NH}_{3}(\mathrm{o})$ & $\rightarrow$ & $\mathrm{NH}_{4}^{+}(I=1)$ & $\mathrm{N}_{2}$ & $1.43(-9)$ & 0.00 & 0.00 & $1.43(-9)$ & 6 & $5 / 8$ \\
\hline \multicolumn{11}{|c|}{$\mathrm{H}_{3}^{+}+\mathrm{O}$} \\
\hline $\mathrm{H}_{3}^{+}(\mathrm{o})$ & $\mathrm{O}$ & $\rightarrow$ & $\mathrm{OH}^{+}$ & $\mathrm{H}_{2}(\mathrm{o})$ & $7.98(-10)$ & -0.156 & 1.41 & $1.18(-9)$ & 9 & 1 \\
\hline $\mathrm{H}_{3}^{+}(\mathrm{o})$ & $\mathrm{O}$ & $\rightarrow$ & $\mathrm{H}_{2} \mathrm{O}^{+}$ & $\mathrm{H}$ & $3.42(-10)$ & -0.156 & 1.41 & $5.05(-10)$ & 9 & \\
\hline $\mathrm{H}_{3}^{+}(\mathrm{p})$ & $\mathrm{O}$ & $\rightarrow$ & $\mathrm{OH}^{+}$ & $\mathrm{H}_{2}(\mathrm{o})$ & $3.99(-10)$ & -0.156 & 1.41 & $5.89(-10)$ & 9 & $1 / 2$ \\
\hline $\mathrm{H}_{3}^{+}(\mathrm{p})$ & $\mathrm{O}$ & $\rightarrow$ & $\mathrm{OH}^{+}$ & $\mathrm{H}_{2}(\mathrm{p})$ & $3.99(-10)$ & -0.156 & 1.41 & $5.89(-10)$ & 9 & $1 / 2$ \\
\hline $\mathrm{H}_{3}^{+}(\mathrm{p})$ & $\mathrm{O}$ & $\rightarrow$ & $\mathrm{H}_{2} \mathrm{O}^{+}$ & $\mathrm{H}$ & $3.42(-10)$ & -0.156 & 1.41 & $5.05(-10)$ & 9 & \\
\hline
\end{tabular}


R. Le Gal et al.: Interstellar chemistry of nitrogen hydrides in dark clouds

Table B.2. New dissociative recombination (DR) reaction rates and branching ratios.

\begin{tabular}{|c|c|c|c|c|c|c|c|c|c|c|c|}
\hline \multicolumn{6}{|c|}{ Chemical reactions $^{a}$} & $\begin{array}{c}\begin{array}{c}\alpha \\
\mathrm{cm}^{3} \mathrm{~s}^{-1}\end{array} \\
\mathrm{DR} \text { of } \mathrm{H}_{3}^{+}\end{array}$ & $\beta$ & $\gamma$ & $\begin{array}{c}k^{b} \\
\mathrm{~cm}^{3} \mathrm{~s}^{-1} \\
\end{array}$ & References & $N S B R$ \\
\hline $\begin{array}{l}\mathrm{H}_{3}^{+}(\mathrm{o}) \\
\mathrm{H}_{3}^{+}(\mathrm{o}) \\
\mathrm{H}_{3}^{+}(\mathrm{p}) \\
\mathrm{H}_{3}^{+}(\mathrm{p}) \\
\mathrm{H}_{3}^{+}(\mathrm{p})\end{array}$ & $\begin{array}{l}\mathrm{e}^{-} \\
\mathrm{e}^{-} \\
\mathrm{e}^{-} \\
\mathrm{e}^{-} \\
\mathrm{e}^{-}\end{array}$ & $\begin{array}{l}\rightarrow \\
\rightarrow \\
\rightarrow \\
\rightarrow \\
\rightarrow\end{array}$ & $\begin{array}{l}\mathrm{H}_{2}(\mathrm{o}) \\
\mathrm{H} \\
\mathrm{H}_{2}(\mathrm{o}) \\
\mathrm{H}_{2}(\mathrm{p}) \\
\mathrm{H} \\
\end{array}$ & $\begin{array}{l}\mathrm{H} \\
\mathrm{H} \\
\mathrm{H} \\
\mathrm{H} \\
\mathrm{H} \\
\end{array}$ & $\mathrm{H}$ & $\begin{array}{c}\text { DR of } \mathrm{H} \\
2.51(-8) \\
4.87(-8) \\
0.92(-8) \\
0.92(-8) \\
3.56(-8) \\
\end{array}$ & $\begin{array}{c}0.16 \\
0.16 \\
-0.73 \\
-0.73 \\
-0.73\end{array}$ & $\begin{array}{c}-1.01 \\
-1.01 \\
0.98 \\
0.98 \\
0.98 \\
\end{array}$ & $\begin{array}{l}1.61(-8) \\
3.13(-8) \\
9.94(-8) \\
9.94(-8) \\
3.86(-7)\end{array}$ & $\begin{array}{l}1,2 \\
1,2 \\
1,2 \\
1,2 \\
1,2 \\
\end{array}$ & $\begin{array}{l}1 / 2 \\
1 / 2\end{array}$ \\
\hline \multicolumn{12}{|c|}{ DR of nitrogen hydrides } \\
\hline $\mathrm{N}_{2} \mathrm{H}^{+}$ & $\mathrm{e}^{-}$ & $\rightarrow$ & $\mathrm{N}_{2}$ & $\mathrm{H}$ & & $2.77(-7)$ & -0.50 & 0.00 & $3.43(-6)$ & 3 & \\
\hline $\mathrm{N}_{2} \mathrm{H}^{+}$ & $\mathrm{e}^{-}$ & $\rightarrow$ & $\mathrm{NH}$ & $\mathrm{N}$ & & $2.09(-8)$ & -0.50 & 0.00 & $2.59(-7)$ & 3 & \\
\hline $\mathrm{NH}_{2}^{+}(\mathrm{o})$ & $\mathrm{e}^{-}$ & $\rightarrow$ & $\mathrm{NH}$ & $\mathrm{H}$ & & $1.17(-7)$ & -0.50 & 0.00 & $6.41(-7)$ & 4,5 & \\
\hline $\mathrm{NH}_{2}^{+}(\mathrm{p})$ & $\mathrm{e}^{-}$ & $\rightarrow$ & $\mathrm{NH}$ & $\mathrm{H}$ & & $1.17(-7)$ & -0.50 & 0.00 & $6.41(-7)$ & 4,5 & \\
\hline $\mathrm{NH}_{2}^{+}(\mathrm{o})$ & $\mathrm{e}^{-}$ & $\rightarrow$ & $\mathrm{N}$ & $\mathrm{H}$ & $\mathrm{H}$ & $1.71(-7)$ & -0.50 & 0.00 & $9.37(-7)$ & 4,5 & \\
\hline $\mathrm{NH}_{2}^{+}(\mathrm{p})$ & $\mathrm{e}^{-}$ & $\rightarrow$ & $\mathrm{N}$ & $\mathrm{H}$ & $\mathrm{H}$ & $1.71(-7)$ & -0.50 & 0.00 & $9.37(-7)$ & 4,5 & \\
\hline $\mathrm{NH}_{2}^{+}(\mathrm{o})$ & $\mathrm{e}^{-}$ & $\rightarrow$ & $\mathrm{N}$ & $\mathrm{H}_{2}(\mathrm{o})$ & & $1.20(-8)$ & -0.50 & 0.00 & $6.57(-8)$ & 4,5 & \\
\hline $\mathrm{NH}_{2}^{+}(\mathrm{p})$ & $\mathrm{e}^{-}$ & $\rightarrow$ & $\mathrm{N}$ & $\mathrm{H}_{2}(\mathrm{p})$ & & $1.20(-8)$ & -0.50 & 0.00 & $6.57(-8)$ & 4,5 & \\
\hline $\mathrm{NH}_{3}^{+}(\mathrm{p})$ & $\mathrm{e}^{-}$ & $\rightarrow$ & $\mathrm{NH}_{2}(\mathrm{p})$ & $\mathrm{H}$ & & $7.75(-8)$ & -0.50 & 0.00 & $4.25(-7)$ & 6 & $1 / 2$ \\
\hline $\mathrm{NH}_{3}^{+}(\mathrm{p})$ & $\mathrm{e}^{-}$ & $\rightarrow$ & $\mathrm{NH}_{2}(\mathrm{o})$ & $\mathrm{H}$ & & $7.75(-8)$ & -0.50 & 0.00 & $4.25(-7)$ & 6 & $1 / 2$ \\
\hline $\mathrm{NH}_{3}^{+}(\mathrm{o})$ & $\mathrm{e}^{-}$ & $\rightarrow$ & $\mathrm{NH}_{2}(\mathrm{o})$ & $\mathrm{H}$ & & $1.55(-7)$ & -0.50 & 0.00 & $8.49(-7)$ & 6 & 1 \\
\hline $\mathrm{NH}_{3}^{+}(\mathrm{p})$ & $\mathrm{e}^{-}$ & $\rightarrow$ & $\mathrm{NH}$ & $\mathrm{H}$ & $\mathrm{H}$ & $1.55(-7)$ & -0.50 & 0.00 & $8.49(-7)$ & 6 & \\
\hline $\mathrm{NH}_{3}^{+}(\mathrm{o})$ & $\mathrm{e}^{-}$ & $\rightarrow$ & $\mathrm{NH}$ & $\mathrm{H}$ & $\mathrm{H}$ & $1.55(-7)$ & -0.50 & 0.00 & $8.49(-7)$ & 6 & \\
\hline $\mathrm{NH}_{4}^{+}(I=2)$ & $\mathrm{e}^{-}$ & $\rightarrow$ & $\mathrm{NH}_{2}(\mathrm{o})$ & $\mathrm{H}$ & $\mathrm{H}$ & $1.22(-7)$ & -0.60 & 0.00 & $9.39(-7)$ & 7 & 1 \\
\hline $\mathrm{NH}_{4}^{+}(I=1)$ & $\mathrm{e}^{-}$ & $\rightarrow$ & $\mathrm{NH}_{2}(\mathrm{o})$ & $\mathrm{H}$ & $\mathrm{H}$ & $8.07(-8)$ & -0.60 & 0.00 & $6.21(-7)$ & 7 & $2 / 3$ \\
\hline $\mathrm{NH}_{4}^{+}(I=1)$ & $\mathrm{e}^{-}$ & $\rightarrow$ & $\mathrm{NH}_{2}(\mathrm{p})$ & $\mathrm{H}$ & $\mathrm{H}$ & $4.03(-8)$ & -0.60 & 0.00 & $3.10(-7)$ & 7 & $1 / 3$ \\
\hline $\mathrm{NH}_{4}^{+}(I=0)$ & $\mathrm{e}^{-}$ & $\rightarrow$ & $\mathrm{NH}_{2}(\mathrm{o})$ & $\mathrm{H}$ & $\mathrm{H}$ & $6.11(-8)$ & -0.60 & 0.00 & $4.70(-7)$ & 7 & $1 / 2$ \\
\hline $\mathrm{NH}_{4}^{+}(I=0)$ & $\mathrm{e}^{-}$ & $\rightarrow$ & $\mathrm{NH}_{2}(\mathrm{p})$ & $\mathrm{H}$ & $\mathrm{H}$ & $6.11(-8)$ & -0.60 & 0.00 & $4.70(-7)$ & 7 & $1 / 2$ \\
\hline $\mathrm{NH}_{4}^{+}(I=2)$ & $\mathrm{e}^{-}$ & $\rightarrow$ & $\mathrm{NH}_{2}(\mathrm{o})$ & $\mathrm{H}_{2}(\mathrm{o})$ & & $1.88(-8)$ & -0.60 & 0.00 & $1.45(-7)$ & 7 & 1 \\
\hline $\mathrm{NH}_{4}^{+}(I=1)$ & $\mathrm{e}^{-}$ & $\rightarrow$ & $\mathrm{NH}_{2}(\mathrm{o})$ & $\mathrm{H}_{2}(\mathrm{o})$ & & $6.27(-9)$ & -0.60 & 0.00 & $4.83(-8)$ & 7 & $1 / 3$ \\
\hline $\mathrm{NH}_{4}^{+}(I=1)$ & $\mathrm{e}^{-}$ & $\rightarrow$ & $\mathrm{NH}_{2}(\mathrm{o})$ & $\mathrm{H}_{2}(\mathrm{p})$ & & $6.27(-9)$ & -0.60 & 0.00 & $4.83(-8)$ & 7 & $1 / 3$ \\
\hline $\mathrm{NH}_{4}^{+}(I=1)$ & $\mathrm{e}^{-}$ & $\rightarrow$ & $\mathrm{NH}_{2}(\mathrm{p})$ & $\mathrm{H}_{2}(\mathrm{o})$ & & $6.27(-9)$ & -0.60 & 0.00 & $4.83(-8)$ & 7 & $1 / 3$ \\
\hline $\mathrm{NH}_{4}^{+}(I=0)$ & $\mathrm{e}^{-}$ & $\rightarrow$ & $\mathrm{NH}_{2}(\mathrm{o})$ & $\mathrm{H}_{2}(\mathrm{o})$ & & $9.40(-9)$ & -0.60 & 0.00 & $7.23(-8)$ & 7 & $1 / 2$ \\
\hline $\mathrm{NH}_{4}^{+}(I=0)$ & $\mathrm{e}^{-}$ & $\rightarrow$ & $\mathrm{NH}_{2}(\mathrm{p})$ & $\mathrm{H}_{2}(\mathrm{p})$ & & $9.40(-9)$ & -0.60 & 0.00 & $7.23(-8)$ & 7 & $1 / 2$ \\
\hline $\mathrm{NH}_{4}^{+}(I=2)$ & $\mathrm{e}^{-}$ & $\rightarrow$ & $\mathrm{NH}_{3}(\mathrm{o})$ & $\mathrm{H}$ & & $8.00(-7)$ & -0.60 & 0.00 & $6.16(-6)$ & 7 & 1 \\
\hline $\mathrm{NH}_{4}^{+}(I=1)$ & $\mathrm{e}^{-}$ & $\rightarrow$ & $\mathrm{NH}_{3}(\mathrm{o})$ & $\mathrm{H}$ & & $2.66(-7)$ & -0.60 & 0.00 & $2.05(-6)$ & 7 & $1 / 3$ \\
\hline $\mathrm{NH}_{4}^{+}(I=1)$ & $\mathrm{e}^{-}$ & $\rightarrow$ & $\mathrm{NH}_{3}(\mathrm{p})$ & $\mathrm{H}$ & & $5.33(-7)$ & -0.60 & 0.00 & $4.10(-6)$ & 7 & $2 / 3$ \\
\hline $\mathrm{NH}_{4}^{+}(I=0)$ & $\mathrm{e}^{-}$ & $\rightarrow$ & $\mathrm{NH}_{3}(\mathrm{p})$ & $\mathrm{H}$ & & $8.00(-7)$ & -0.60 & 0.00 & $6.16(-6)$ & 7 & 1 \\
\hline \multicolumn{12}{|c|}{$\mathrm{DR}$ of $\mathrm{H}_{3} \mathrm{O}^{+}$} \\
\hline $\mathrm{H}_{3} \mathrm{O}^{+}$ & $\mathrm{e}^{-}$ & $\rightarrow$ & $\mathrm{OH}$ & $\mathrm{H}_{2}(\mathrm{o})$ & & $3.00(-8)$ & -0.50 & 0.00 & $1.64(-7)$ & 6 & $1 / 2$ \\
\hline $\mathrm{H}_{3} \mathrm{O}^{+}$ & $\mathrm{e}^{-}$ & $\rightarrow$ & $\mathrm{OH}$ & $\mathrm{H}_{2}(\mathrm{p})$ & & $3.00(-8)$ & -0.50 & 0.00 & $1.64(-7)$ & 6 & $1 / 2$ \\
\hline $\mathrm{H}_{3} \mathrm{O}^{+}$ & $\mathrm{e}^{-}$ & $\rightarrow$ & $\mathrm{OH}$ & $\mathrm{H}$ & $\mathrm{H}$ & $2.60(-7)$ & -0.50 & 0.00 & $1.42(-6)$ & 6 & \\
\hline $\mathrm{H}_{3} \mathrm{O}^{+}$ & $\mathrm{e}^{-}$ & $\rightarrow$ & $\mathrm{H}_{2} \mathrm{O}$ & $\mathrm{H}$ & & $1.10(-7)$ & -0.50 & 0.00 & $6.03(-7)$ & 6 & \\
\hline $\mathrm{H}_{3} \mathrm{O}^{+}$ & $\mathrm{e}^{-}$ & $\rightarrow$ & $\mathrm{H}_{2}(\mathrm{o})$ & $\mathrm{H}$ & $\mathrm{O}$ & $2.80(-9)$ & -0.50 & 0.00 & $1.53(-8)$ & 6 & $1 / 2$ \\
\hline $\mathrm{H}_{3} \mathrm{O}^{+}$ & $\mathrm{e}^{-}$ & $\rightarrow$ & $\mathrm{H}_{2}(\mathrm{p})$ & $\mathrm{H}$ & $\mathrm{O}$ & $2.80(-9)$ & -0.50 & 0.00 & $1.53(-8)$ & 6 & $1 / 2$ \\
\hline
\end{tabular}

Notes. Numbers in parentheses are power of 10. ${ }^{(a)} \mathrm{o}$ and $\mathrm{p}$ stand for ortho and para states respectively. As a spherical top with four identical protons, the ammonium ion exists in three nuclear spin states noted as in Faure et al. (2013): para $(I=0)$, meta $(I=2)$, and ortho $(I=1)$. We note that the meta and ortho species are inverted in Rist et al. (2013). ${ }^{(b)}$ Rates $k=\alpha(T / 300)^{\beta} \exp (-\gamma / T)$ have been computed for a $10 \mathrm{~K}$ temperature. (c) NSBR stands for nuclear-spin branching ratio. These were combined with the overall rate coefficients taken from the cited references, e.g. Dos Santos et al. (2007).

References. (1) Dos Santos et al. (2007); (2) McCall et al. (2004); (3) Vigren et al. (2012); (4) Mitchell (1990); (5) Thomas et al. (2005); (6) Jensen et al. (2000); (7) Öjekull et al. (2004). 
A\&A 562, A83 (2014)

Table B.3. Neutral-neutral chemical reaction rates and branching ratios considered.

\begin{tabular}{|c|c|c|c|c|c|c|c|c|c|}
\hline & \multicolumn{4}{|c|}{ Chemical reactions } & $\alpha$ & $\beta$ & $\gamma$ & $\begin{array}{c}k^{a} \\
\mathrm{~cm}^{3} \mathrm{~s}^{-1}\end{array}$ & References \\
\hline \multicolumn{10}{|c|}{$\mathrm{N}$ to $\mathrm{N}_{2}$ conversion } \\
\hline $\mathrm{N}$ & $\mathrm{OH}$ & $\rightarrow$ & NO & $\mathrm{H}$ & $8.9(-11)$ & 0.20 & 0.00 & $4.5(-11)$ & datasheet by Bergeat from $\mathrm{KIDA}^{b}$ \\
\hline $\mathrm{N}$ & NO & $\rightarrow$ & $\mathrm{N}_{2}$ & $\mathrm{O}$ & $7.2(-11)$ & 0.44 & 12.7 & $4.6(-12)$ & fit of calculations from Jorfi \& Honvault (2009) \\
\hline $\mathrm{N}$ & $\mathrm{CN}$ & $\rightarrow$ & $\mathrm{N}_{2}$ & $\mathrm{C}$ & $8.8(-11)$ & 0.42 & 0.00 & $2.1(-11)$ & Daranlot et al. (2012) \\
\hline $\mathrm{N}$ & $\mathrm{CH}$ & $\rightarrow$ & $\mathrm{CN}$ & $\mathrm{H}$ & $1.7(-10)$ & 0.18 & 0.00 & $9.0(-11)$ & datatsheet by Smith \& Loison from KIDA ${ }^{b}$ \\
\hline $\mathrm{C}$ & NO & $\rightarrow$ & $\mathrm{CN}$ & $\mathrm{O}$ & $6.0(-11)$ & -0.16 & 0.00 & $1.0(-10)$ & Chastaing et al. (2000); Bergeat (1999) \\
\hline $\mathrm{C}$ & NO & $\rightarrow$ & $\mathrm{CO}$ & $\mathrm{N}$ & $9.0(-11)$ & -0.16 & 0.00 & $1.6(-10)$ & Chastaing et al. (2000); Bergeat (1999) \\
\hline \multicolumn{10}{|c|}{$\mathrm{O}$ to $\mathrm{O}_{2}$ conversion } \\
\hline $\mathrm{O}$ & $\mathrm{OH}$ & $\rightarrow$ & $\mathrm{O}_{2}$ & $\mathrm{H}$ & $4.0(-11)$ & 0.00 & 0.00 & $4.0(-11)$ & datasheet by Loison et al. from KIDA ${ }^{b}$ \\
\hline
\end{tabular}

Notes. Numbers in parentheses are powers of 10. ${ }^{(a)}$ Rates of the form $k=\alpha(T / 300)^{\beta} \exp (-\gamma / T)$ have been computed at $10 \mathrm{~K} .{ }^{(b)}$ Wakelam et al. (2012). 